\title{
JOSÉ ORTIZ DE VILLENA, AMIGO Y EDITOR DE LOPE DE VEGA*
}

\author{
Felipe B. Pedraza Jiménez (Universidad de Castilla-La Mancha)
}

Cita Recomendada: Felipe B. Pedraza Jiménez, «José Ortiz de Villena, amigo y editor de Lope de Vega», Anuario Lope de Vega. Texto, literatura, cultura, XXVIII (2022), pp. 205-261.

DOI: <https://doi.org/10.5565/rev/anuariolopedevega.448>

Fecha de recepción: 10 de agosto de 2021 / Fecha de aceptación: 7 de septiembre de 2021

\section{Resumen}

En el artículo se estudia el entorno del viejo Lope de Vega, su relación con la Congregación de San Pedro Mártir de Sacerdotes Seculares Naturales de Madrid y la labor de José Ortiz de Villena en la edición póstuma de las obras del Fénix. Como apéndice se editan todos los poemas y notas prologales de Ortiz de Villena que han llegado a nosotros.

Palabras Clave: José Ortiz de Villena; Lope de Vega; Congregación de Sacerdotes Seculares Naturales de Madrid; Ediciones y cuestiones ecdóticas.

ABstract: José Ortiz de Villena, Friend and Editor of Lope de Vega.

This article discusses the environment of Lope de Vega's last years, his relationship with the Congregation of Saint Peter Martyr of Secular Clergy from Madrid, and José Ortiz de Villena's preparation of the posthumous edition of Fenix's works. Ortiz de Villena's surviving poems and prologue notes are included in the appendix.

Keywords: José Ortiz de Villena; Lope de Vega; Congregation of Secular Clergy from Madrid; Publishing and Textual Criticism.

* Este trabajo es fruto de la investigación que viene desarrollando el Instituto Almagro de teatro clásico. Se incluye dentro del proyecto PID2020-117749GB-C21, aprobado por el ministerio de Ciencia e Innovación. 
EL ENTORNO DEL VIEJO LOPE

$\Upsilon$ odos tenemos en la memoria el arranque del poema que nuestro común maestro, directo o indirecto, José Manuel Blecua Teijeiro [1956:82] consideraba «el romance sentencioso más bello de toda nuestra literatura»:
A mis soledades voy,
de mis soledades vengo,
porque para andar conmigo,
me bastan mis pensamientos. ${ }^{1}$

El estudio de Guillermo Serés señaló cómo, en este exordio de la composición, el poeta «introduce los conceptos centrales y recurrentes en torno al definitorio de "soledad"». ${ }^{2}$ Parece claro que, a la altura de 1632, Lope desea trasmitir una imagen de filósofo estoico, retirado del mundo, sobre cuyas locuras y desatinos reflexiona y medita.

Sin duda, esta actitud entronca con el «nudo de desengaños» que Rozas percibió en la obra del autor en la etapa de senectud. ${ }^{3}$ En este sentido, el poema desvela autorreferencialmente la actitud del autor en esa coyuntura vital, social y política. Pero nunca debemos confundir la autorreferencialidad lírica con la verdad literal de los enunciados métricos. Lope quería proyectar la imagen del que vive en soledad, apartado del tráfago mundano; pero la realidad era, presumiblemente, muy otra. Los octosílabos del romance no reflejan los hechos observables, sino un desideratum, una suerte de recreación lírica de cierto desengañado sentir y de un impostado orgullo estoico.

1. El romance lo recita el protagonista, Fernando, en la escena IV del acto I (Lope de Vega, La Dorotea, pp. 141-144). Parece que el poeta tenía cierta impaciencia por colocarlo cuanto antes en la «acción en prosa». A diferencia de lo que ocurre con otros versos incluidos en la fábula celestinesca, se señala enfáticamente la autoría: «Oye un romance de Lope».

2. Serés [1998:331]. En el artículo, además del análisis de las «fuentes y motivos principales» del romance, encontrará el lector un excelente estado de la cuestión que resume cuanto se ha dicho sobre el célebre poema (al menos, cuanto se había dicho hasta finales del siglo xx).

3. Rozas [1982:32-42]. Véase también el tema del desengaño en Pedraza [2008]. 
En los últimos años de su vida, el poeta no estuvo solo, sino rodeado de gente que lo admiraba y lo quería. Siempre gozó de esa privilegiada situación entre sus contemporáneos, aunque él nunca renunciara a trazar en su creación literaria el halo, sí es no es trágico, del que nada quiere saber con un mundo dominado por la ambición y la envidia. En su invocación de la soledad hay una suerte de coquetería de la desdicha, a la que fue muy inclinado en todos los momentos de su vida.

Tanto su primer testamento (otorgado el 4 de febrero de 1627), en que se dejan mandas para un crecido número de amigos, como las multitudinarias exequias tras su muerte, los numerosos actos de homenaje y los cientos de poetas que acudieron a exaltar su fama póstuma dan buena cuenta de la amplia red de contactos sociales que asistía y protegía al genio. Su condición de familiar del Santo Oficio no fue obstáculo para que mantuviera relaciones de amistad con el círculo de intelectuales judeoconversos del que formaban parte Fernando Cardoso, Miguel Silveira, Antonio Enríquez Gómez, Isabel Enríquez, Manuel Fernandes de Vila Real... Probablemente, Juan Pérez de Montalbán pudo ser elemento catalizador de estas amistades. A Lope «le dio repentinamente un desmayo» mientras asistía a «unas conclusiones de medicina y filosofía que defendió tres días el doctor Fernando Cardoso» (Pérez de Montalbán, Fama póstuma, pp. 24-25). Y el portugués es el único laico al que se encomendó una oración fúnebre en honor de Lope, cuya edición está dedicada y presumiblemente sufragada por el duque de Sessa.

A pesar de la estrecha vinculación del poeta con su mecenas, que militaba en una inoperante oposición al gobierno de la monarquía católica, no dejaba de tener contacto con los grupos del poder: Olivares, Luis Méndez de Haro (marqués de Heliche), el duque de Medina de las Torres, o con el mismo monarca. Los encargos palaciegos no faltan en estos tiempos: La selva sin amor (1627), La noche de san Juan (1631), Versos a la fiesta del palacio nuevo (1633), El Amor enamorado (1635)... Lo que no es obstáculo para que sintiera un profundo disgusto ante su fracasada pretensión de ser cronista real, un radical desacuerdo con medidas gubernamentales como la negativa a autorizar la impresión de nuevas comedias y novelas, una agobiante angustia ante la devaluación de la moneda (el famoso resello) o un permanente resquemor ante la irrupción de «los pájaros nuevos», favorecidos desde palacio.

Uno de los apoyos con que contó en los últimos años fue el grupo de amigos y admiradores que encontró en la Venerable e Ilustre Congregación de San Pedro Apóstol de Presbíteros Seculares Naturales de Madrid, que había fundado Jeróni- 
mo de Quintana en 1619. ${ }^{4}$ En ella ingresó Lope el 29 de junio de 1625 y fue elegido capellán mayor el 2 de julio de $1628 .^{5}$

\section{José ORTiz DE VillenA}

El mismo año de 1625 en que ingresó Lope, se afiliaron también sus buenos amigos Juan Pérez de Montalbán, Francisco de Quintana (sobrino del fundador y orador en las honras fúnebres que se rindieron al poeta) y Lorenzo Van der Hammen y León (al que había dedicado la epístola sexta de las publicadas en La Circe, 1624). Unos años más tarde, en 1634, Francisco López de Aguilar (a cuyo nombre apareció un texto prologal, escrito en realidad por Lope, en La Dorotea) ${ }^{6}$

José Ortiz de Villena se había adelantado unos días a sus compañeros de intereses literarios e intelectuales. El acta de ingreso en la Congregación, cuya reproducción me ha facilitado Jesús María López Sotillo, archivero de la institución, está datada el 13 de mayo de 1625, y figura con el número 92 (la de Lope tiene el número 95). Esta proximidad en la incorporación a la sociedad eclesiástica podría indicar que Ortiz de Villena indujo o, al menos, animó a sus amigos y conocidos a solicitar la admisión en la misma.

4. Las constituciones merecieron la aprobación del cardenal de Toledo, el infante don Fernando de Austria, el día 15 de junio. La primera asamblea tuvo lugar el 25 del mismo mes y año en la capilla del hospital de La Latina (véase Mayor Gimeno 1964:20). Cuando ya estaba en prensa este artículo, apareció un nuevo e interesante volumen sobre Los orígenes de la Congregación Sacerdotal de San Pedro Apóstol (ed. J. R. Folgado García, Xerión, Aranjuez, 2021). En él se encuentran, entre otros bien documentados artículos, dos directamente relacionados con Lope de Vega: uno de Abraham Madroñal Durán («Lope de Vega, miembro de la Congregación de Sacerdotes Naturales de Madrid», pp. 113-137) y otro de Jesús Ponce Cárdenas («Lope de Vega, congregante: apostillas a un romance a San Pedro Apóstol», pp. 138-160).

5. Esta circunstancia le sirvió de excusa para rechazar un envite que no era de su agrado. Es bien conocido el fragmento de la carta a don Antonio de Mendoza en que alude al cargo: «Estos días se decretó en el senado cómico que Luis Vélez, don Pedro Calderón y el doctor Mescua hiciesen una comedia, y otra, en competencia suya, el doctor Montalbán, el doctor Godínez y el licenciado Lope de Vega, y que se pusiese un jarro de plata en premio. Respondí que era este año capellán mayor de la Congregación, y que para el que viene acetaba el desafío. Grande invención, desautorizada cosa, gran plato para el vulgo» (Lope de Vega, Epistolario, tomo IV, p. 102).

6. Mayor Gimeno (1964:351-371) ofrece en su libro una «Relación de los congregantes que brillaron entre los mejores escritores madrileños». Además, incluye la reproducción facsimilar del acta de ingreso de Lope (entre las pp. 20 y 21) y de Calderón (entre las pp. 26 y 27), que se incorporó el 20 de mayo de 1663 y fue capellán mayor en el año 1666. 


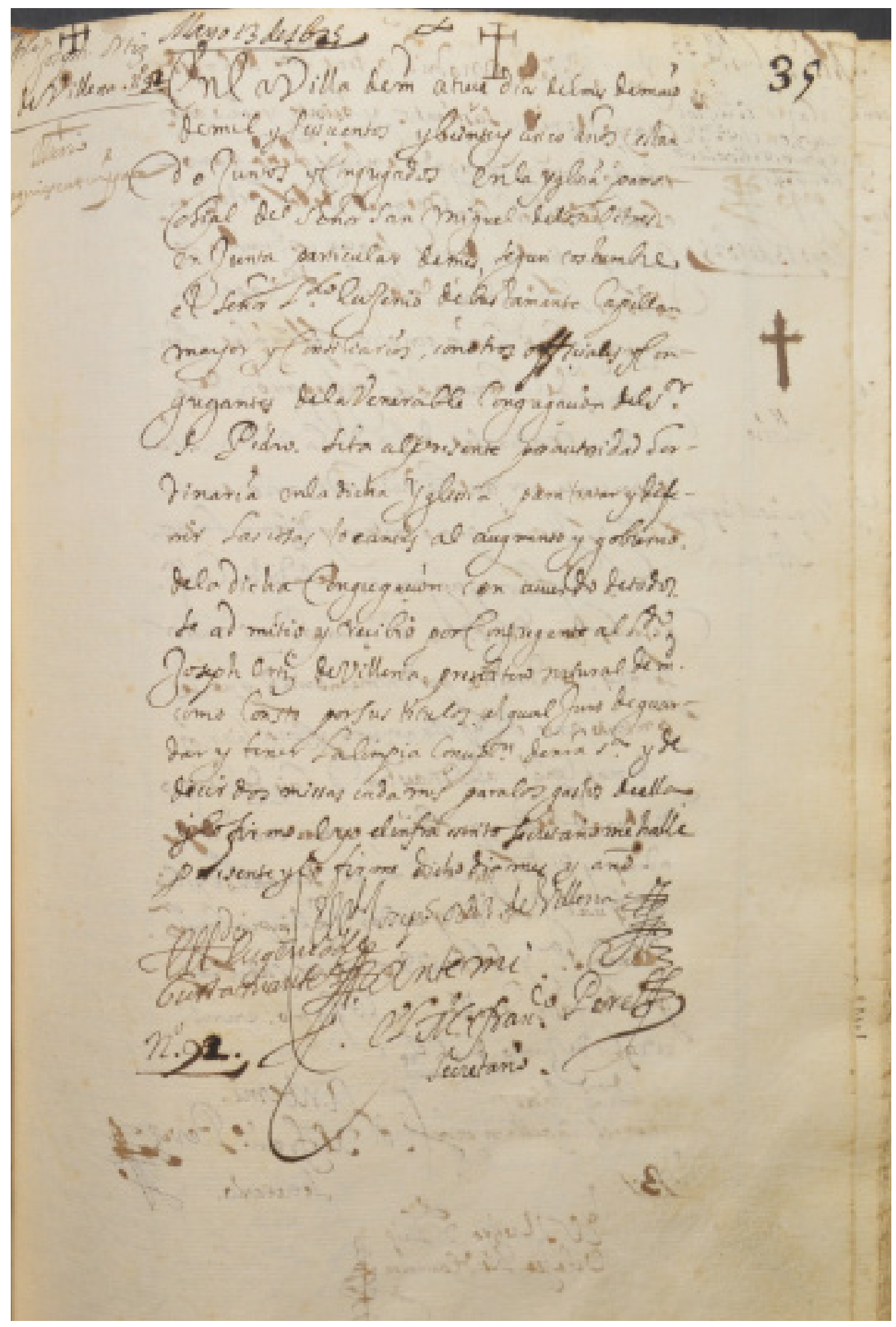

Imagen 1: Acta de ingreso en la Venerable e Ilustre Congregación de San Pedro Apóstol de Presbíteros Seculares Naturales de Madrid. 
No conocemos la fecha de nacimiento de Ortiz de Villena. Y hasta hace unos días desconocía la data de su muerte. En el documento de los Sacerdotes Naturales de Madrid se anota que «Murió» y se añade piadosamente "Resquiescat in pace», pero no se consignan día, mes y año. Sin embargo, la generosidad de mi buen amigo y excelente lopista Carlos Peña López me ha revelado que Antonio de Capmany y Montpalau (homónimo y descendiente del autor de Centinela contra franceses) la había registrado en su Museo histórico (vol. 1, p. 543): el 18 de junio de 1647. Añade el cronista madrileño, aunque de apellidos catalanes, que «murió como sacerdote ejemplar e ilustrado» y fue enterrado en «la real parroquia de San Pedro en esta corte». Fue miembro, como tantos otros escritores de su tiempo (Cervantes, Lope, Calderón...) de la Venerable Orden Tercera de San Francisco. Según Capmany, esta piadosa institución «le lloró como a su más celoso enfermero, la humanidad doliente como a su protector compasivo y la incipiente Congregación de Presbíteros Naturales de Madrid, como a su mejor columna».

Probablemente, el acta de defunción se encuentre en la parroquia de La Paloma; pero, dado el estado de ruina del edificio, tras la explosión fortuita de gas del 20 de enero de 2021, habrá que esperar un poco para disponer de una copia de la misma.

En su epístola electrónica, Carlos Peña me comunica, además, esta otra noticia:

En 1624 Inés Ortiz de Frías dispuso en su testamento la fundación de un patronato en el convento de Santa Clara de Madrid (según el documento FUENTE PELAYO, C.8,D.29 de la Sección Nobleza del Archivo Histórico Nacional), cuya capellanía ostentaría, al parecer, José Ortiz de Villena, al menos entre 1643 y 1644 (según el documento FUENTE PELAYO, C.8,D.34 del mismo fondo).

No se han localizado hasta ahora, que yo sepa, otros documentos administrativos (salvo el señalado por Carlos Peña) que nos den luz sobre sus andanzas. Es muy probable que se puedan encontrar nuevos datos en los archivos parroquiales de Madrid que no han desaparecido por guerras, incendios y otros funestos avatares. Seguro que nuestros amigos historiadores, más duchos que yo en estas rebuscas, en cuanto se lo propongan, darán con documentos que nos permitan precisar datos y circunstancias relativos a su discreta existencia.

Sí tenemos algunos testimonios de carácter literario en torno a su persona. El más antiguo se debe a la pluma de Lope de Vega, que lo elogió, con las generalidades acostumbradas, en el Laurel de Apolo (1630): 


\begin{abstract}
De Josef de Villena, yo te aseguro, venturoso río, por dulce filomena, todo el laurel que de su ingenio fío; ninguno en tu ribera o tu montaña de más virtud las letras acompaña.
\end{abstract}

(Lope de Vega, Laurel de Apolo, silva VII, vv. 325-330)

Juan Pérez de Montalbán lo incluyó amistosamente en el «Índice o catálogo de todos los pontífices, cardenales, arzobispos, obispos, escritores de libros, predicadores, poetas y varones ilustres en todo género de letras que ha tenido y tiene la insigne villa de Madrid, reconocidos por hijos verdaderamente suyos», que publicó en Para todos (1632). La nota es escueta y poco comprometida: «191. El licenciado Josef de Villena, poeta lírico, agudo y claro» (p. 870).

Probablemente, en ese momento, Ortiz de Villena era poeta sobre su palabra, más intencional que efectivo. De esta circunstancia y de su relación ancilar, vagamente discipular, con Lope de Vega deduzco que debía de ser joven en la década de 1630, por lo que creo que hay que considerarlo miembro, quizá adelantado, de la generación nacida a principios de siglo, coetáneo, o poco menos, de Juan Pérez de Montalbán, de Pedro Calderón de la Barca o de Francisco de Quintana. Pudo nacer en la última década del siglo XVI.

Con buena lógica, Nicolás Antonio no se acordó de él en la Bibliotheca Hispana nova. Su producción - al menos, la que ha llegado a nosotros- es muy escasa, muy breve y enteramente circunstancial.

El primero que le prestó cierta atención fue, según mis noticias, José Antonio Álvarez de Baena (Hijos ilustres de Madrid, III, pp. 23-24). Guiado probablemente por Pérez de Montalbán, como él mismo señala, se preocupó de reunir algunos datos sobre su vida, extrajo los que ya conocemos del acta de ingreso en la Congregación de San Pedro Apóstol, y señaló los poemas que nos han llegado y las ediciones en que colaboró.

Los contados escritos que conocemos de Ortiz de Villena están vinculados al mundillo literario. ${ }^{7}$ Se trata de cuatro poemas; en realidad, poco más de tres y me-

7. Carlos Peña me señala que Mesonero Romanos [1858:I, xxxix] atribuye al «licenciado José Ortiz de Villena» una comedia titulada Antonio Roca. Poco o nada sabemos de este asunto, salvo que en la primera lista de El peregrino en su patria figura el título de Antonio Roca como obra de Lope, y que se conservan dos manuscritos: uno, con ese título, que perteneció a lord Holland y hoy se con- 
dio, ya que el tercero retoma versos e imágenes del primero de los publicados. El más antiguo es una silva a Lope de Vega, tras su muerte, y vio la luz en la Fama póstuma (1636). El segundo se consagra a la memoria de Juan Pérez de Montalbán y se incluyó en las Lágrimas panegíricas (1638) preparadas por Pedro Grande de Tena, miembro también de la Congregación. La composición en tercetos Al túmulo inmortal de frey Lope Félix de Vega Carpio del hábito de San Juan y las octavas Al Santísimo Sacramento del altar se imprimieron en los preliminares de Las fiestas del Santísimo Sacramento (1644). El resto son notas prologales en prosa a los tres volúmenes póstumos de Lope de Vega de cuya edición se encargó.

Para que el lector interesado pueda acceder a lo que, hoy por hoy, parece la obra completa de Ortiz de Villena, edito como apéndice de este artículo tanto los versos elegíacos como las prosas introductorias. Las citas de estos opúsculos que jalonan mi discurso remiten a él.

\title{
AMISTAD E IDEAS LITERARIAS
}

En este puñadito de textos subraya el autor su vinculación afectiva y su admiración literaria a Lope y a Pérez de Montalbán. En los epígrafes aparecen reiteradamente expresiones como «su amigo», «su grande amigo y aficionado», «su verdadero amigo»... Los versos y la labor editorial están presididos por este sentido de la amistad:

\footnotetext{
Solo sacar pretendo del intento dar a entender que fui su fiel amigo y que estimé su gran merecimiento.
}

(Al túmulo y fama inmortal de Lope de Vega)

\begin{abstract}
serva en la biblioteca de Lord Ilchester (Londres), y otro rotulado Antonio Roca o la muerte más venturosa, que fue propiedad del duque de Osuna y pasó a la Biblioteca Nacional de España (MS/15205). Véanse el estudio de Dixon [1971] y la edición de McGrady [2009]. El nombre de Ortiz de Villena no aparece en los grandes catálogos dramáticos de Barrera y Urzáiz [2002], que sí registran la existencia del drama Antonio Roca (Barrera 1860:428, 435 y 528; Urzáiz 2002:386 y 653). Parece poco probable que el venerable sacerdote se lanzara a la redacción de una comedia sin más experiencia — que sepamos — que la de lector y editor de algunas de ellas.
\end{abstract}


En los textos dedicados a Lope, Ortiz de Villena desgrana las ideas literarias compartidas con el amigo muerto, al que considera superior a todos sus contemporáneos. Quizá haya que ver una velada alusión a Góngora en los pareados de la Elegía funeral de la Fama póstuma:

Fuiste, sin duda, del Parnaso el ave, venciendo al cisne que volar más sabe.

La idea y las palabras, adaptadas al nuevo formato métrico, se repiten con pocos cambios en Al túmulo y fama inmortal...:

Eres, sin duda, del Parnaso el ave que con veloz y levantado vuelo venciste al cisne que volar más sabe.

Como era común entre los intelectuales de la época, considera su creación literaria muy por encima de las que nos legó la antigüedad: ${ }^{\circ}$

No llamo tus conceptos peregrinos, que atrás dejaron griegos y latinos.

(Elegía funeral)

Mas ya faltaste del hispano suelo, atrás dejando griegos y latinos, sin descansar hasta llegar al cielo.

(Al túmulo y fama inmortal...)

Está convencido de que la comedia española es una de las mayores creaciones de su tiempo, por su variedad de tonos y formas y su capacidad para cautivar a todo tipo de oyentes:

8. Recuérdese, por ejemplo, la Invectiva a las comedias que prohibió Trajano y apología por las nuestras de Francisco de Barreda, incluida en El mejor príncipe, Trajano Augusto...: «Más bien lograda [que en la antigüedad] está hoy la tragedia, o sea tragicomedia o tragedia, que eso es disputar sobre el nombre. Más levantado trono la realza, más pompa la acompaña, más decoro la corona, más variedad la enriquece» (f. 130r). Fernando Cardoso, en su Oración fúnebre (pp. 475-476), también se suma a esta valoración: «Príncipe de los cómicos, te respetarán las edades mejor que a Eurípides Grecia, ni que a Terencio Roma. [...] Puedo afirmar sin ofensa que más pensamientos, más sutilezas encierra Lope solo que todos los poetas de la antigüedad». 
Tus diversas comedias son sirenas que a los oyentes adormecen tanto, que obligan a olvidar las graves penas.

Allí se ve tan eficaz el llanto, las fábulas y historias retratadas, que parece verdad y es dulce encanto.

En el orbe se logran estimadas, dando gusto y dotrina al relevante ingenio, por que siga sus pisadas.

Y para el vulgo rudo que, ignorante, aborrece el manjar costoso, guisa el plato del gracioso estravagante, con que les hartas de contento y risa, gustando de mirar sayal grosero más que sutil y cándida camisa.

(Al túmulo y fama inmortal...)

Uno de los caballos de batalla de las prosas y versos de Ortiz de Villena es la pureza de la lengua, que ve encarnada en Lope:

Al fin murió el ingenio, la agudeza, la lengua castellana, la pureza, con que la habló con elegancia tanta...

(Elegía fúnebre)

Y no faltan los ataques a los desmanes hipercultistas de Góngora y sus secuaces, que,

engañados de términos escuros y inauditos, en vez de aumentarla y ennoblecerla, infaman y destruyen nuestra lengua. [...] Porque, con cuatro voces peregrinas y algunos desaforados hipérboles — gran fiesta del ignorante vulgo-, se sueñan muchos haber llegado a la infinita majestad del arte. (La vega del Parnaso)

Algunos puntazos contra los críticos y envidiosos («de los zoílos las censuras vanas»), y la constante exaltación de la obra del amigo — que, al fin, «es de Lope»— completan los conceptos literarios que Ortiz de Villena maneja en sus escritos. 
Como se ve, se trata de un traslado, en miniatura, de las ideas y actitudes que desarrolló el gran poeta en sus polémicas.

\section{ORTIZ DE VILLENA Y LAS EDICIONES PÓSTUMAS DE LOPE}

Ortiz de Villena declara en varias ocasiones que el apoyo que prestó a Lope y a sus herederos tendría que ver con lo que hoy llamamos la recensio. Se atribuye haberle ayudado en la labor de reunir los originales (manuscritos o impresos) utilizados para la configuración de algunos de sus libros. Esta tarea de coleccionista de las obras de su amigo está reconocida por Pérez de Montalbán en la Fama póstuma, al comentar el testamento del dramaturgo:

Al licenciado Josef Ortiz de Villena, por solícito en juntar sus obras para tenerlas como reliquias de tal ingenio, [le dejó] una lámina muy curiosa. ${ }^{9}$

Cayetano Alberto de la Barrera acepta como un hecho, al menos en un caso, que el padre de la comedia española se valió de su ayuda para esta labor de localización de los originales:

Para la Parte veinte y una pidió el autor a su grande amigo el licenciado José Ortiz de Villena, que con solícito afán y gusto colectaba sus originales y borradores, las doce comedias que debía contener. ${ }^{10}$

No nos queda claro si Ortiz de Villena reunía estas piezas en competencia con el duque de Sessa, que — como sabemos por el epistolario— también sentía la pasión de

9. Pérez de Montalbán, Fama póstuma, p. 23. El testamento a que se alude en la cita es el que otorgó el poeta, «con mucho tiempo», el 4 de febrero de 1627. Allí se dice: «Al licenciado Villena, mi grande amigo, ruego lo mismo [que a Francisco de Quintana: «que se acuerde de mí en sus sacrificios y oraciones»] y le dejo un cuadro de santa Catalina de Siena» (Lope de Vega, 27 documentos, p. 150). Sin embargo, esa manda desaparece en el último testamento (quizá por ser más breve y considerarse innecesarias estas precisiones), otorgado el 26 de agosto de 1635, en el que firma como testigo el mismo Ortiz de Villena.

10. Barrera [1973-1974:I, 332-333]. En nota matiza: «Así lo afirma Ortiz de Villena en el prólogo; pero es evidente que Lope no tuvo entonces necesidad del original de su tragedia El castigo sin venganza, que acababa de publicar esmeradamente corregida». Los que hemos tenido la oportunidad de cotejar el texto del autógrafo con el de la edición barcelonesa, podemos poner algún reparo menor a esta conclusión de don Cayetano. 
recoger los manuscritos e impresos del poeta, o si lo hacía de forma colaborativa con el aristócrata, para preservar entre los dos el patrimonio literario de Lope. ${ }^{11}$

Los tres libros en los que intervino sin lugar a dudas son:

\section{VEINTE Y VNA | PARTE | VERDADERA DE LAS | COMEDIAS DEL FENIX} DE | España Frei Lope Felix de Vega Carpio, del Abito de San | Iuan, Familiar del Santo Oficio de la Inquisicion, | Procurador Fiscal de la Camara Apostolica, | sacadas de sus originales. | DEDICADAS A DOÑA ELENA | Damiana de Iuren Samano $y$ Sotomayor [...] | Año [Florón.] 1635. | CON PRIVILEGIO | [Filete.] | En Madrid, Por la viuda de Alonso Martin. | A costa de Diego de Logroño, mercader de libros. | Vendese en sus casas, en la calle Real de las Descalzas.

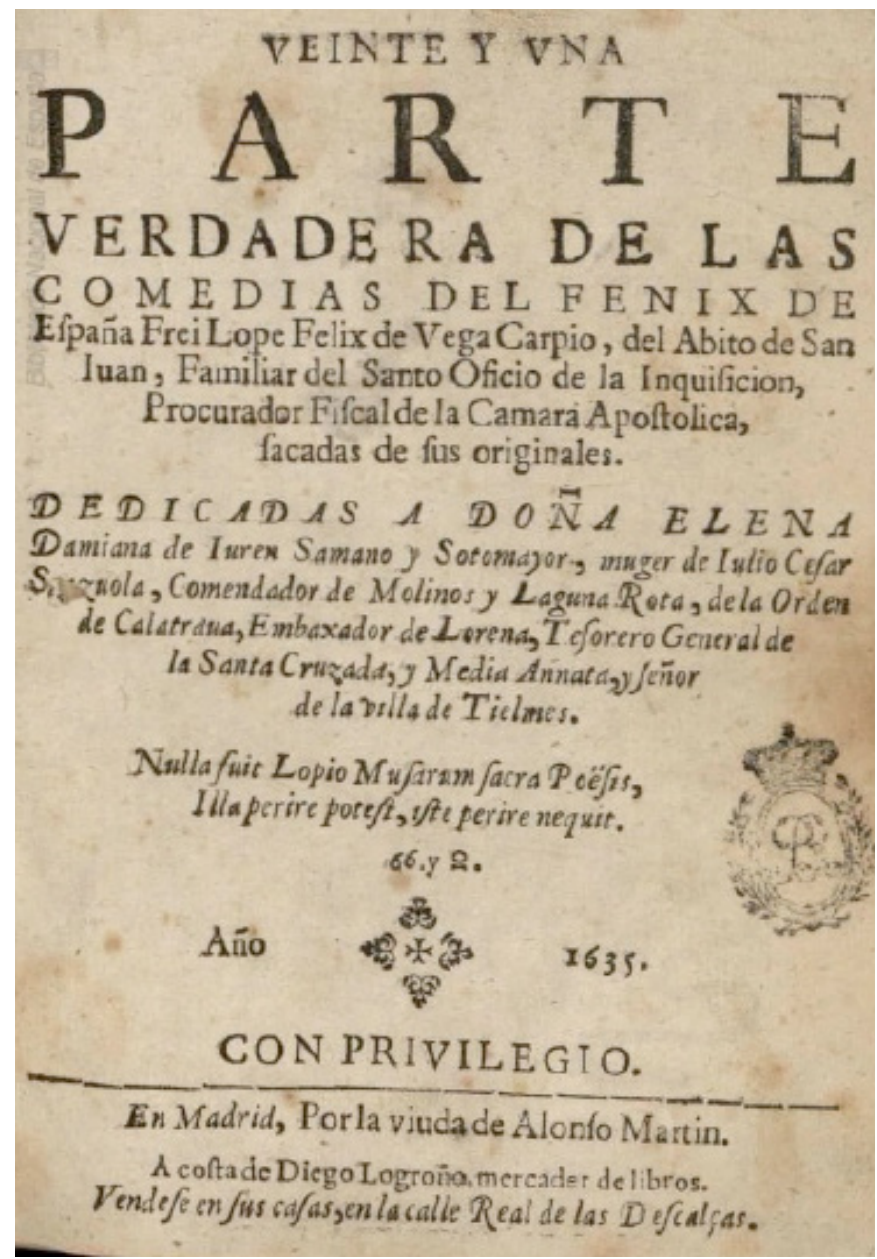

11. El afán coleccionista de don Luis Fernández de Córdoba se evidencia en varias de las cartas de Lope. En la que Amezúa data el 9 de octubre de 1611, pero que se escribió el 15 (véase Peña 2021:133), el poeta comenta con falsa modestia esta afición del aristócrata: «No sé si es sobra de tiempo o falta de gusto juntar vuestra excelencia estos papeles que me escribe; pero, de cualquiera suerte, quisiera que fueran, ya que ignorancias mías, en su original por lo menos...» (Lope de Vega, Epistolario, tomo III, p. 60). En la que Amezúa data conjeturalmente «¿a fines de junio de 1617?», señala las dificultades para recuperar el autógrafo de La dama boba, que era propiedad de Jerónima de Burgos, y le ofrece otros manuscritos (tomo III, p. 308). En otra carta le informa de que «Roque Hernández traslada la comedia con muy buen gusto, sabiendo que lo es de vuestra excelencia el tenerla» (tomo III, p. 369). La espléndida colección de autógrafos que ha llegado a nosotros procede en su mayor parte de la biblioteca del duque (véase Presotto 2000). Quizá alguno pasara por las manos diligentes de Ortiz de Villena. 
1637 LA VEGA DEL PARNASO | POR EL FENIX DE ESPAÑA | Frey Lope Felix de Vega Carpio, del Abito de | San Iuan, Procurador Fiscal de la | Camara Apostolica. | DIRIGIDA | AL EXCELENTISSIMO SEÑOR DON LVIS | Fernandez de Cordoua, Cardona, y Aragon, Duque de Sessa, \&c. $|74|$ [Escudo del mecenas] | En Madrid, En la Imprenta del Reyno, Año 1637.

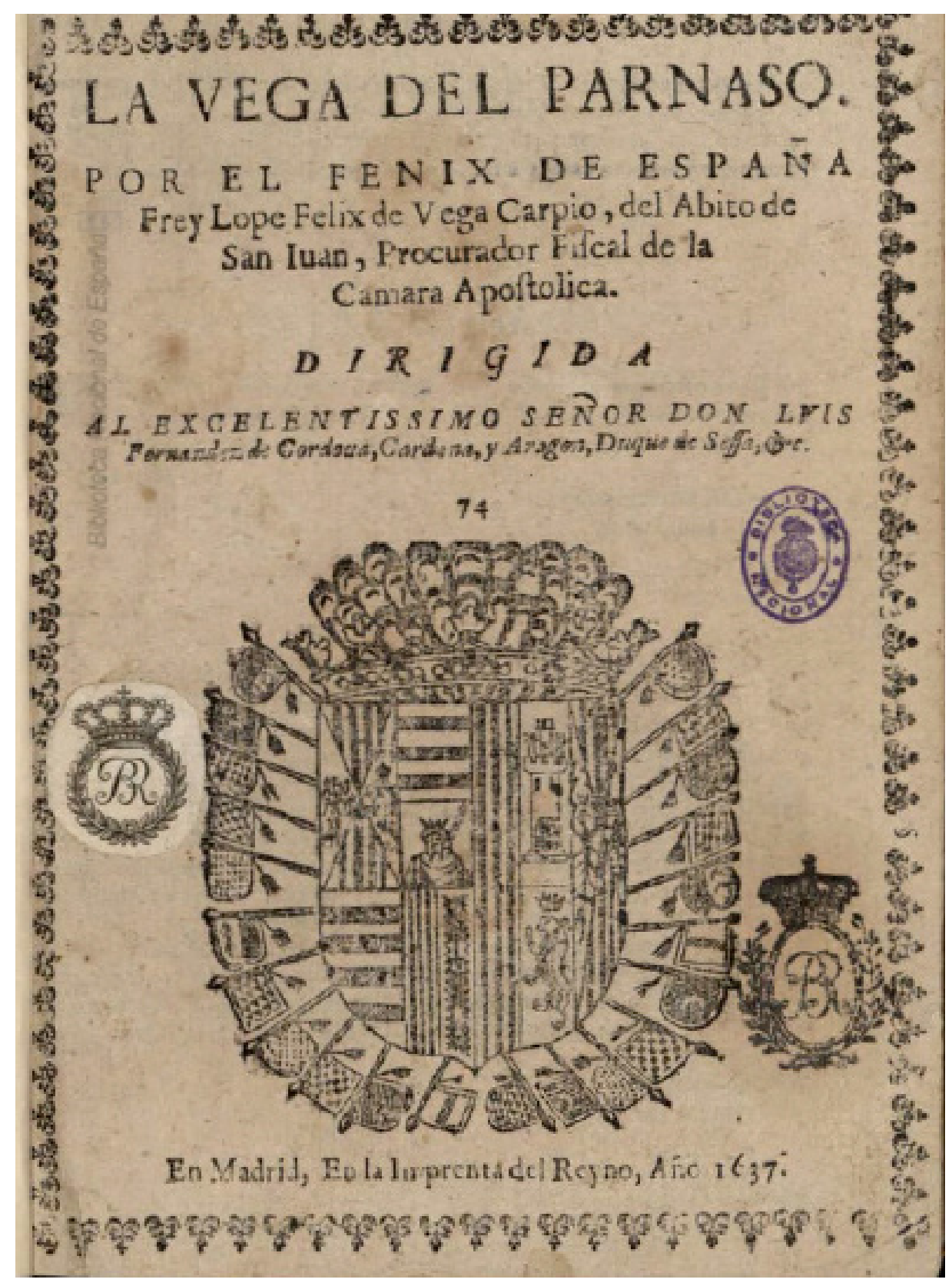


1644 FIESTAS | DEL SANTISSIMO | SACRAMENTO. | REPARTIDAS EN DOZE AVTOS | Sacramentales, con sus Loas, y Entremeses. | Compuestas por el Phenix de España Frey Lope Felix | de Vega Carpio, del Abito de San Iuan. | RECOGIDAS POR EL LICENCIADO IOSEPH ORTIZ DE | Villena, y dedicadas al Tumulo, y Fama inmortal suyo. | [Viñeta con un cáliz y dos ángeles adorándolo.] | Loado sea el Santissimo Sacramento, y la limpia Concepcion de la Virgen | Santissima, Concebida sin mancha de pecado original, y el paso | doloroso de su Martirio, y Soledad. | Con licencia : En Çaragoza, por Pedro Verges, Año M.DC.XXXXIIII. | A costa de Pedro Verges Mercader de libros, En la Calle de Toledo.

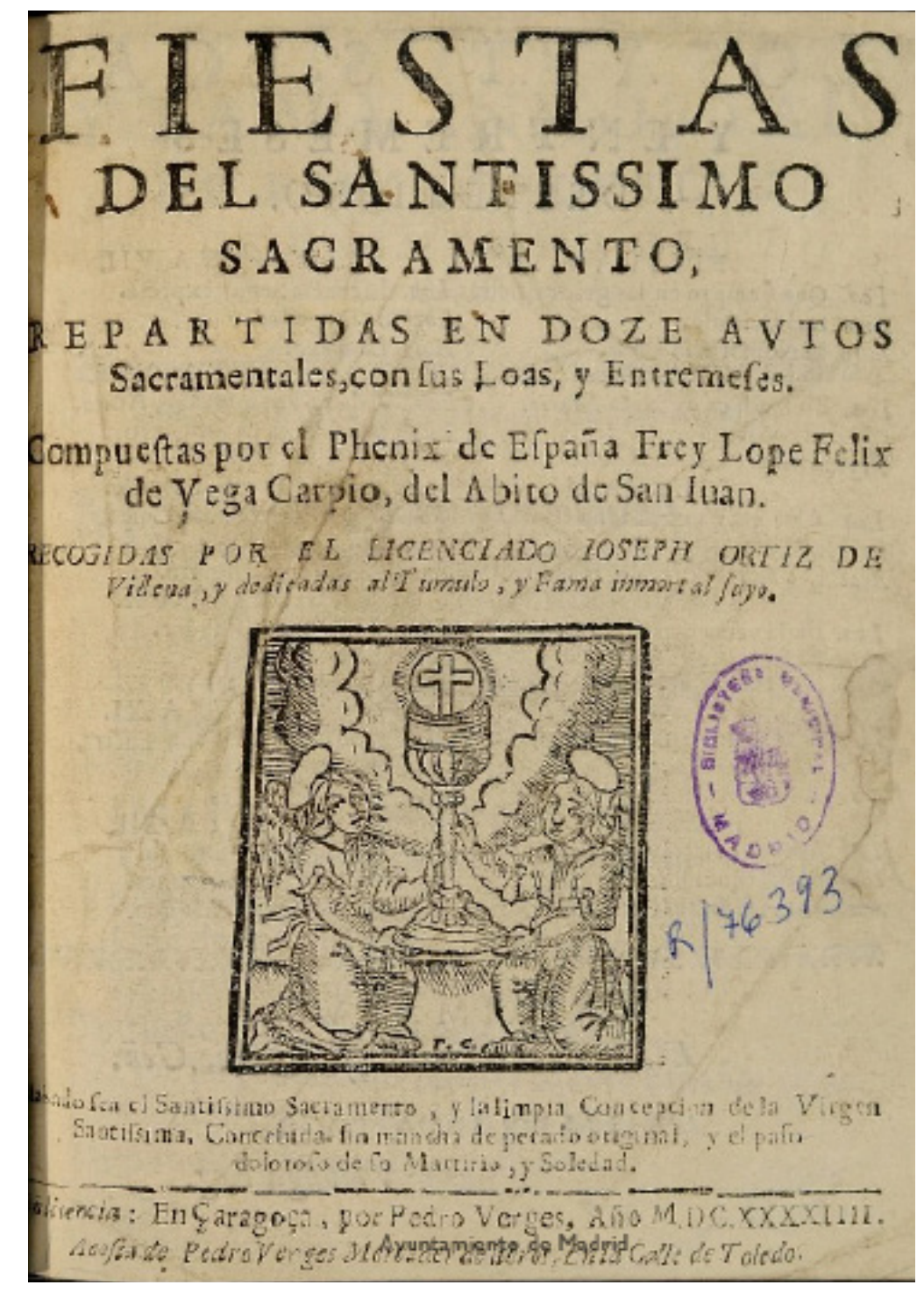

http://revistes.uab.cat/anuariolopedevega 
En estos tres volúmenes aparecen textos prologales con su firma. En el escrito dirigido A los aficionados de frey Lope Félix de Vega Carpio, de la Parte XXI, alude de forma ambigua a la inminente aparición de la Parte XXII:

Después de estas, saldrá también la Parte veinte y dos verdadera, y luego ofrezco La vega del Parnaso, con otras comedias y varias rimas...

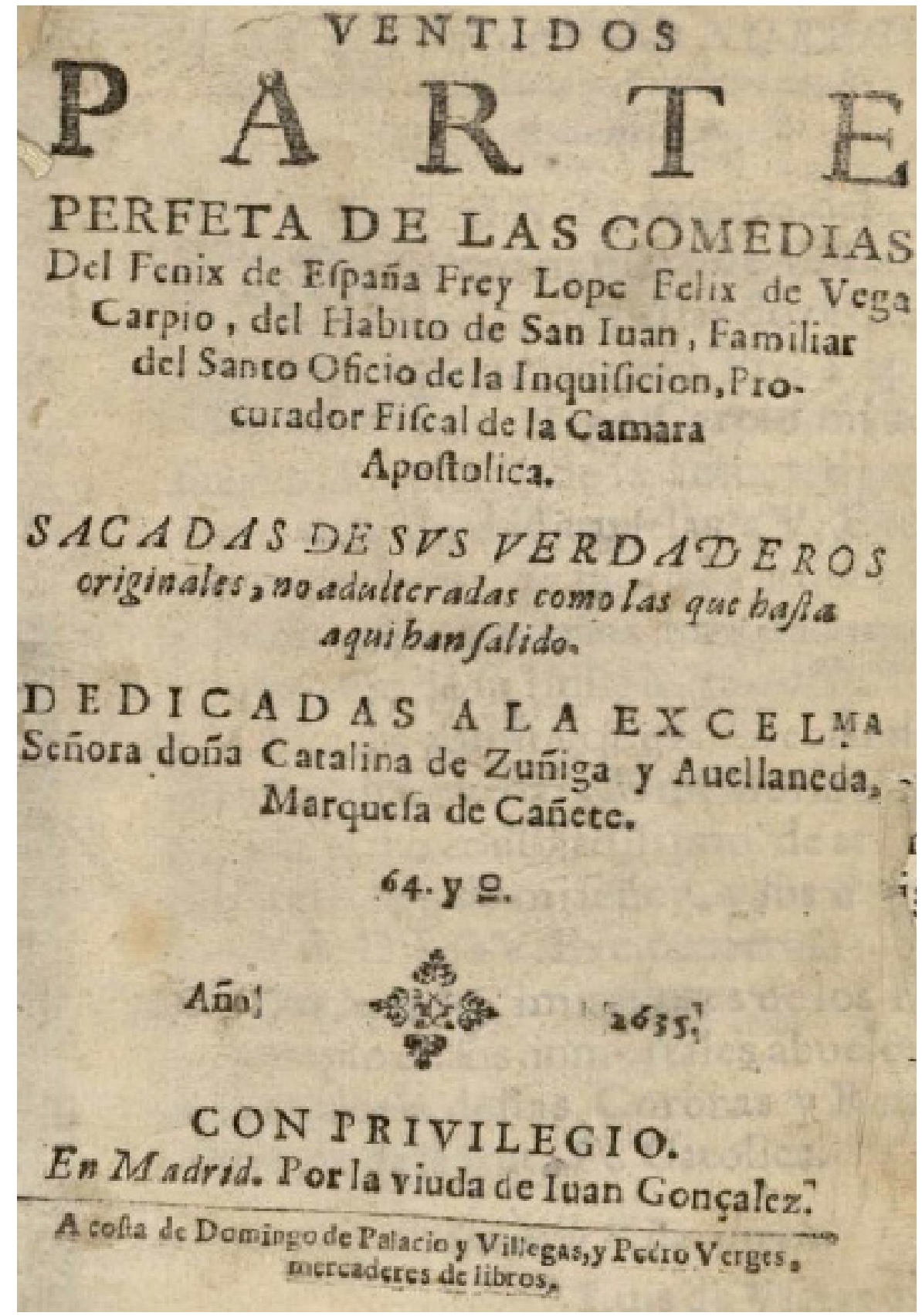


Quizá haya que interpretar que estas líneas son el mero anuncio de un nuevo volumen en cuya publicación Ortiz de Villena no reivindica participación alguna.

En los tres libros en que resulta patente el quehacer de Ortiz de Villena aparecen notas prologales en que se dirige a los aficionados o apasionados de Lope de Vega, y se atribuye el haber reunido, por encargo del autor, los textos que los constituyen. Así, en la Parte XXI sostiene que facilitó al dramaturgo las obras que allí se editan:

habiendo juntado en mi poder la mayor parte de sus obras (que me costó no pequeño trabajo) [...], a persuasión suya le di estas doce comedias, sacadas de sus borradores y originales para darlas a la estampa.

En los preliminares de La vega del Parnaso afirma haber animado a Lope para que reimprimiera los poemas que había ido publicando sueltos, fundamentalmente en la década de 1630; se atribuye la localización de varios impresos perdidos o traspapelados, y destaca su labor de amanuense respecto de algunos manuscritos:

Pedían tantas personas estos versos de Lope que andaban en fragmentos por haberse impreso pocos en diversos tiempos, como escritos a diversos propósitos, y siendo lo que con más estudio se conoce entre sus líricos, que me pareció — cuando era vivopedirle que los juntase, copiándole muchos de los que no estaban impresos y dándole los que no tenía, por cumplir con los deseos de los aficionados a sus obras.

Además, proclama, en mi opinión con suficiente claridad, haber añadido las ocho comedias que completan el volumen que finalmente apareció en 1637:

Y por que le viniese mejor el nombre a La vega del Parnaso, se añadieron las mejores comedias que ha compuesto, por que, como en las vegas hay tanta variedad de plantas, árboles y flores, así pudiesen entretenerse los que la leyeren en tan diversos géneros de poesías, y no siendo menos conforme a su nombre el título del libro.

Basándome en estas palabras y en la estructuración final del volumen, he mantenido en mis ensayos que la incorporación de las ocho comedias es responsabilidad exclusiva de Ortiz de Villena, ya muerto el autor (posiblemente con la aquiescencia de los herederos). ${ }^{12}$ Como saben los entendidos en esta cuestión, Maria

12. Véase Pedraza [1993 y 2014a]. 
Grazia Profeti [1989 y 2006] ha expuesto en distintos escritos la hipótesis contraria, según la cual Lope organizó en todos sus extremos el impreso de La vega del Parnaso, con la inclusión de las piezas dramáticas. ${ }^{13}$

Naturalmente, el que la iniciativa fuera de Ortiz de Villena y que, en mi concepto, modificara sustancialmente el proyecto de Lope, no es obstáculo para aceptar, como señala Gómez Sánchez-Ferrer, que este conjunto de versos líricos y comedias proporcionara a

la poesía del madrileño una nueva vida editorial como objeto de consumo, preparado para satisfacer por última vez a un amplio público, devoto del autor y ansioso por que cayesen en sus manos sus últimas novedades dramáticas y líricas (Gómez Sánchez-Ferrer 2015:532).

Atendiendo a este fenómeno capital en la trasmisión de la obra, la edición crítica del Instituto Almagro estudió, fijó y anotó las treinta y cuatro piezas que configuraban el volumen de 1637. Quizá algún día (si encuentro apoyo para el proyecto) podamos publicar la reconstrucción del poemario que Lope decía tener «en estado», es decir, listo para la imprenta en 1633, y que hubo de ampliarse con nuevos versos líricos hasta la primavera de 1635, antes de la intervención de Ortiz de Villena, tras la muerte del autor.

En el caso del último libro en que intervino, las Fiestas del Santísimo Sacramento, informa A los aficionados de frey Lope Félix de Vega Carpio de que la iniciativa de reunir el volumen e imprimirlo es exclusivamente suya, como tendremos oportunidad de ver.

\section{Las tareas ecdóticas de Ortiz de Villena}

En cualquier caso, resulta claro que las labores a que alude el propio Ortiz de Villena y las que podemos intuir del examen de los impresos en que participó, afectan a los primeros y los últimos estadios del proceso ecdótico: la recensio y lo que podríamos llamar la constitutio voluminis, si se admite este nuevo latinajo en el argó de

13. En el prólogo a la edición crítica de la obra se confrontan amistosamente las dos posturas (Pedraza 2015:28-35). 
la ciencia ecdótica, tan pródiga en ellos. No parece que interviniera en la constitutio textus de cada poema u obra dramática. Su participación, muy activa, afectó, en el caso de La vega del Parnaso, a la configuración del tomo impreso que finalmente llegó a manos de los lectores.

Por lo que he podido comprobar, el sacerdote amigo no procedió a la collatio de diversos testimonios de un mismo texto. Creo - ya me desmentirán los análisis ulteriores si es necesario - que no se encuentran rastros de cotejo de distintas fuentes. No recuerdo, en las obras que he editado (once poemas de La vega del Parnaso y El castigo sin venganza), o cuya edición he seguido (el conjunto de La vega del Parnaso), rastros de correcciones ope codicum. Sí las hay ope ingenii, pero se trata de enmiendas elementales: subsanación de erratas y poco más.

Probablemente, la proximidad y las evidencias de la última voluntad del autor presentaban como no solo innecesaria sino impertinente esta labor. En el concepto de Ortiz de Villena, había poco que cotejar. La utilización de los materiales se escalonó, según creo, siguiendo esta pauta:

1. Si existía un impreso autorizado por el autor, se convertía en la fuente única de la nueva edición.

2. Si no disponía de un impreso, recurría a un autógrafo, tan limpio como fuera posible, y lo incorporaba al legajo que había de entregarse a la censura y, posteriormente, a los cajistas.

3. Si el manuscrito no pasaba de borrador, lo copiaba con el mayor cuidado, aunque, desde nuestra actual perspectiva, no siempre con el acierto que desearíamos.

Este proceso de preparación de las ediciones póstumas no difiere del que el mismo que Lope siguió en vida. En el caso de las obras dramáticas, la tarea más ardua era hacerse con los manuscritos originales, lo que implicaba una renegociación con los autores de comedias. A pesar del énfasis con que las portadas proclaman que son «sacadas de sus originales», en más de un caso se vale de impresos ya en circulación o de copias manuscritas por terceros.

En lo que se refiere a las piezas líricas de La vega del Parnaso, puedo afirmar, con razonable conocimiento de causa, que este fue el método seguido. Lo que Lope, con la ayuda de Ortiz de Villena, preparó para pasar los trámites administrativos y 
para los componedores de la Imprenta del Reino, fue un legajo en que reunió las sueltas ya publicadas y los manuscritos en limpio de las obras que permanecían inéditas. El texto de los distintos poemas en La vega... es siempre un codex descriptus respecto a estos testimonios previos. Las ediciones sueltas que han llegado a nosotros nos permiten comprobar este aserto. No conozco de primera mano el proceso seguido con las comedias, pero creo que fue similar al descrito para las piezas líricas.

Sí he reflexionado algo sobre la trasmisión de $E l$ castigo sin venganza, al que me he tenido que acercar al preparar mi edición y al trabajarlo fragmentariamente en la clase de crítica textual con mis alumnos. Las observaciones que he podido realizar confirman lo dicho para los textos líricos. Tengo la impresión de que el ejemplar de la edición presumiblemente sevillana rescatado hace unos meses en la Biblioteca Nacional de España (T-55351-29), que lleva por título Un castigo sin venganza. Cuando Lope quiere, quiere, no modifica sustancialmente esta hipótesis.

La Parte XXI parece seguir con razonable fidelidad la suelta barcelonesa de Pedro Lacavallería, que a su vez parte de un manuscrito que debió de entregarle Manuel Álvarez Vallejo, que estaba de gira en Barcelona en los meses de julio y agosto de 1634. La aprobación de fray Francisco Palau, que figura al frente del impreso, se firmó en el convento de Santa Catalina de Barcelona, el 23 de julio. Unos días después, el 6 de agosto, murió María Riquelme y fue enterrada en el convento de Santa Mónica, muy cerca de la casa de comedias del Hospital de la Santa Cruz. ${ }^{14}$

Es probable que el manuscrito que finalmente llegó a manos de los componedores fuera una copia, esencialmente fiel al autógrafo de Lope, pero en la que se habían incorporado pequeñas modificaciones, quizá nacidas de la representación. Así ocurre, por ejemplo, en el v. 1863, que el autógrafo de Lope reparte entre las réplicas de los dos personajes:

$\begin{array}{cc}\text { Casandra } & \text { ¿Cómo te va de tristeza, } \\ & \text { Federico? } \\ \text { Federico } & \quad \text { En tanto mal } \\ & \begin{array}{l}\text { responderé a vuestra alteza } \\ \text { que es mi tristeza inmortal. (vv. 1862-1865) }\end{array}\end{array}$

14. Sobre estas circunstancias y su posible relación con el soneto de las Rimas de Burguillos «Yacen en este mármol la blandura...» he tratado en un capitulillo del artículo «Lope y sus actores» (Pedraza 2018:170-172). 
Es también el texto que ofrece la recién descubierta suelta sevillana. En cambio, tanto en la barcelonesa de 1634 como en la Parte XXI y en la edición lisboeta de 1647, con menos lógica dramática pero quizá con mayores facilidades para el recitado de los actores, aparece todo el v. 1863 en boca de Casandra:

\author{
CASANDra ¿Cómo te va de tristeza, \\ Federico, en tanto mal? \\ FEDERICo Responderé a vuestra alteza \\ que es mi tristeza inmortal. (vv. 1862-1865)
}

Son muchas otras las pequeñas variantes que se dan entre el autógrafo y los impresos, que no sabemos si atribuir a la labor regulizadora de Álvarez Vallejo, en su función de director de la compañía; al amanuense que sacó las copias para los actores y apuntes; o a los componedores de Pedro Lacavallería. Algunas pudieran responder a los usos lingüísticos de los escribanos o de los cajistas implicados en el proceso. Me ocuparé solo de dos ejemplos, dramática y literariamente irrelevantes, pero que, por eso mismo, son reveladores de la cadena que se estableció en la trasmisión textual. Sin duda, nadie reparó en estas pequeñeces.

El autógrafo diptonga el verbo templar y su derivado: tiempla (vv. 1187, 1288), destiemplan (v. 1866). En cambio, los impresos leen templa y templó (v. 1187), templa (v. 1288), destemplan (v. 1866): ${ }^{15}$

$\begin{array}{ll}1187 & \text { tiempla } M: \text { templa } S: \text { templó } B P L \\ 1288 & \text { tiempla } M: \text { templa } S B P L \\ 1866 & \text { destiemplan } M: \text { destemplan } S B P L\end{array}$

El autógrafo escribe sistemáticamente madrastra (vv. 255, 319, 648, 778, 978, $1882,1901,2417$ y 2983). En cambio, la suelta barcelonesa, la Parte madrileña y la edición lisboeta leen unas veces madrastra (vv. 255, 319, 978, 2417 y 2983) y otras madrasta (vv. 648, 778, 1882 y 1901). Podríamos imaginar que en el caso de la edición lisboeta hubo un conato de regularización en el v. 648, pronto olvidado.

15. Aunque es obvio, precisemos que las iniciales elegidas responden a los siguientes testimonios: $M=$ autógrafo; $S=$ s.i., s.l., s.a. (¿Sevilla?); $B=$ Barcelona, 1634; $P=$ Parte XXI, Madrid, 1635; $L=$ Lisboa, 1647 . 
La suelta de Sevilla no coincide exactamente con los impresos conocidos desde antiguo: madrasta (vv. 255, 319); madrastra (vv. 648, 778, 978, 1882, 1901, 2417, 2983).

Si reducimos a esquema las nueve ocurrencias, el resultado es este (se señalan las apariciones de madrastra y se dejan en blanco las de madrasta):

\begin{tabular}{|c|c|c|c|c|c|c|c|c|c|}
\hline madrastra & 255 & 319 & 648 & 778 & 978 & 1882 & 1901 & 2417 & 2983 \\
\hline & $M$ & $M$ & $M$ & $M$ & $M$ & $M$ & $M$ & $M$ & $M$ \\
\hline & & & $S$ & $S$ & $S$ & $S$ & $S$ & $S$ & $S$ \\
\hline & $B$ & $B$ & & & $B$ & & & $B$ & $B$ \\
\hline & $P$ & $P$ & & & $P$ & & & $P$ & $P$ \\
\hline & $L$ & $L$ & $L$ & & $L$ & & & $L$ & $L$ \\
\hline
\end{tabular}

En este y en otros casos que he podido comprobar, la Parte XXI coincide significativamente con la suelta barcelonesa, siempre que esta se separa del autógrafo. Parece claro que en la primavera de 1635, al presentar a la censura los textos que habían de integrar la Parte, Lope, Ortiz de Villena o ambos de consuno incorporaron un ejemplar del texto impreso, que fue también el utilizado por los componedores del taller de la viuda de Alonso Martín.

Como viene practicando el grupo Prolope (recuérdese el caso de La dama boba), lo lógico es tomar como texto base el más próximo a la voluntad del autor de cada pieza editada. No es razonable reproducir servilmente lo que nos ofrece la Parte. En consecuencia, procede acudir al autógrafo para fijar el texto y relegar al aparato de variantes las que arroja el cotejo con la Parte $X X I$ y con otros impresos. ${ }^{16}$

\section{El ERROR de LA PARTE XXII}

El procedimiento de agavillar los originales de los textos, impresos siempre que se podía, o manuscritos cuando no existían o no se encontraban ejemplares de ediciones sueltas, explica el error que se cometió en la Parte XXII, cuyo proceso administrativo

16. Es también la fórmula que seguimos en el Instituto Almagro al editar La vega del Parnaso. Cada poema y cada comedia tiene su vida textual propia que hay que reconstruir de forma independiente para acercarnos a lo que el poeta quiso trasmitir a los lectores-espectadores contemporáneos y a la posteridad. 
inició Lope de Vega. Sabemos por las rebuscas archivísticas de Fernando Bouza [2011:351] que el poeta había solicitado los permisos oportunos el 6 de marzo de 1626:

digo que yo querría imprimir dos libros que son el tomo veinte y uno y veinte y dos de mis obras, de las cuales hago presentación a vuestra alteza...

El consejo de Castilla, consecuente con la determinación de no autorizar nuevas publicaciones de comedias ni novelas, denegó el permiso solicitado e hizo constar que ya existían otros libros con esos mismos rótulos, editados de forma fraudulenta.

Cuando se levantó la disparatada disposición administrativa, el poeta volvió a presentar, en la primavera de 1635, una nueva petición para publicar la Parte XXII. Las aprobaciones de Valdivielso y de Florencio de Vera y Chacón tienen fechas de 12 y 26 de mayo. Adelantándose a esta última, el licenciado Lorenzo de Iturrizarra concedió la licencia para imprimir el 14 de mayo. La suma del privilegio se otorga el 21 de junio. Se tiran los pliegos durante el verano y se remata la estampa un mes después de muerto Lope: la fe de erratas es de 28 de setiembre y la tasa, de 2 de octubre.

Como es sabido, al menos desde que Cayetano Alberto de la Barrera [1860:448] lo señaló en su Catálogo bibliográfico y biográfico del teatro antiguo español, en este volumen se incluyó, en lugar del texto de Amor, pleito y desafío de Lope, el de Ganar amigos de Juan Ruiz de Alarcón. El propio Barrera, en la Nueva biografía de Lope de Vega, trataría de explicar con detalle lo sucedido:

Faltole vida al insigne poeta para ver terminada la impresión de uno y otro volumen [las partes XXI y XXII]. Al tiempo de su fallecimiento, la de dicha Parte vigesimasegunda debía de llegar, cuando más, a la octava comedia, y aquella desgraciada circunstancia hubo de dar origen a la extraña sustitución que por descuido, ignorancia o aceleramiento se verificó en el tomo. De las piezas en él comprendidas había dispuesto Lope de Vega que la novena fuese su drama Amor, pleito y desafí (cuyo MS autógrafo, firmado en 23 de noviembre de 1621, existe en la Biblioteca Nacional, procedente de la colección del señor Durán), y en lugar de ella se insertó, con el mismo título y bajo el nombre de Lope, la de don Juan Ruiz de Alarcón y Mendoza denominada por su autor Ganar amigos. En efecto, el drama de Ruiz de Alarcón Ganar amigos había salido por primera vez atribuido a Lope, y con el tal título de Amor, pleito y desafío, en el ya mencionado tomo de varios: Parte veinte y cuatro de las comedias del Fénix de España, Lope de Vega Carpio, y las mejores que hasta ahora han salido. Im- 
preso en Zaragoza, año de 1632 y 1633 . Quedó entretanto, y permanece todavía, inédito el verdadero y legítimo de Lope Amor, pleito y desafío. ${ }^{17}$

Todo nos lleva a confirmar — ¡una vez más! — que el dramaturgo no seguía el proceso de edición de sus comedias con el cuidado y la atención que proclamaba en prólogos y dedicatorias. Aunque Pérez de Montalbán en la Fama póstuma (pp. 2425) insiste en las premoniciones de Lope sobre su muerte, lo cierto es que hizo vida normal hasta el 24 de agosto, día de San Bartolomé. ${ }^{18}$ Hay que suponer que hasta ese momento se ocupó de la composición e impresión de las Partes XXI y XXII, que para esas fechas ya tenían que estar muy adelantadas, aunque parece claro que se dio prioridad a la $X X I$ (tasa del 5 de setiembre) y que la XXII no se ultimó hasta unas semanas más tarde (tasa del 2 de octubre).

Creo que no cabe echar las culpas del desaguisado a su yerno Luis de Usátegui (o Usategui, que no sabemos cómo articularía su apellido el interesado) ni a ningún otro acólito. Debió de ser el propio Lope el que no se percató de que el impreso que entregó a la censura y más tarde a los componedores no correspondía a su obra, sino a la de Ruiz de Alarcón que se había impreso a su nombre y con el título cambiado. José Ortiz de Villena no aparece en la Parte XXII, por lo que no se le puede hacer responsable de este trueque.

En todo caso, como sabemos todos los que andamos en estas lides, en el universo tipográfico los lapsus son tan inevitables como frecuentes, y no tienen más explicación racional que la existencia, negada sin fundamento por algunos, de los duendes de imprenta. ${ }^{19}$

17. Barrera [1973-1974:I, 333]. Los versos de Lope se publicaron en el tomo de Comedias inéditas (Rivadeneyra, Madrid, 1873), preparado por Sancho Rayón y el marqués de la Fuensanta del Valle en la «Colección de libros raros y curiosos», y, más tarde, en el tomo X de la nueva edición de la Academia al cuidado de Federico Ruiz Morcuende (Madrid, 1930).

18. Por errata o error, Pérez de Montalbán (Fama póstuma, p. 24) señala el 18, «viernes, día de San Bartolomé», pero hay que enmendar la fecha, ya que al santo se le dedicaba y se le sigue dedicando el 24 de agosto. Juan Antonio de la Peña, en el preámbulo Al lector de su opúsculo A la fama inmortal del Fénix de Europa (f. 4), precisa los datos: «Enfermó de un grave accidente que le dio el día de San Bartolomé, asistiendo a unas conclusiones de medicina que se tuvieron en el Hospital de los Escoceses. Murió a 27 de agosto, víspera del doctor de la iglesia San Agustín, a las cinco de la tarde».

19. Quien se interese por estas extrañas criaturas, de tamaño diminuto, carácter tímido y huidizo pero travieso, y hábitos nocturnos, debe acudir a una de las pocas monografías científicas en que se demuestra su indudable existencia y se analizan sus características más notables (Pedraza 2004). 


\section{PARÉNTESIS Y FE DE ERRATAS}

Los duendes que cambiaron los tres mil versos de Amor, pleito y desafío (¡no uno ni dos!) por los de Ganar amigos, también nos han jugado una mala pasada (menos onerosa que la de la Parte XXII) en la edición de una de las obras en que anduvo ocupado Ortiz de Villena. Permítaseme utilizar esta prestigiosa tribuna como fe de erratas de nuestra edición de La vega del Parnaso (2015).

En el ejercicio del cargo de capellán mayor, Lope escribió un culto poema de largo título: Al serenísimo señor don Fernando de Austria, infante de España, cardenal de Roma, su protector, la Congregación de los Sacerdotes Naturales de Madrid dedica esta canción. El borrador autógrafo de esta composición se encuentra en el llamado Códice Pidal, hoy en paradero desconocido, pero cuya copia fotográfica se conserva en el fondo Entrambasaguas de la Universidad de Castilla-La Mancha (E-15384). Es probable que existiera una suelta, de la que no se ha localizado ejemplar alguno. De modo que el más antiguo impreso conservado son los ff. 37-40v de La vega del Parnaso (1637).

A partir de estos testimonios, edité la canción en 2015 (Lope de Vega, La vega del Parnaso, tomo I, pp. 363-390). En ella anuncié la publicación de una dedicatoria en prosa a don Fernando de Austria, que figura en el manuscrito, pero no en el impreso de 1637. Ocupa una posición insólita para este tipo de escritos, al final del poema autógrafo, y dice así:

Estos versos reconocen a vuestra alteza por dueño de la Congregación de Sacerdotes naturales de esta villa como su protector, así por haber nacido en ella vuestra alteza como por ser nuestro dignísimo prelado, y tiene ciento y doce capellanes, cosa no vista en príncipe, y todos ruegan a Nuestro Señor por la vida de vuestra alteza, que guarde muchos años.

El borrador presenta algunas mínimas tachaduras y correcciones sobre e infraescritas:

la

...por dueño de nuestra Congregación...

...y tiene ciento y doce capellanes...

En ella hay 
Este texto y sus variantes constaban en el documento informático que preparé para la imprenta; pero, por razones que no he logrado averiguar, la dedicatoria en prosa no aparece en el impreso, sí las variantes. Solo la innata e invencible inclinación de los duendes de imprenta a la travesura puede explicar semejante desaguisado. Quizá les bastó seleccionar el texto en el documento informático y pulsar la tecla de retorno para borrar, en alguna de las fases de maquetación, las cinco líneas en prosa que deberían haber aparecido al final del poema.

A pesar de que las masas se lanzaron, ávidas de poesía, sobre este texto en cuanto apareció la edición, parece que nadie hasta ahora había advertido la incongruencia de anunciar esta suerte de colofón dedicatorio que después no aparecía. Yo, tampoco, hasta que el destino y la amable invitación de Prolope me ha llevado a considerar de nuevo las obras en cuya edición intervino el venerable Ortiz de Villena. Con esta fe de erratas me adelanto a los ceñudos aristarcos, y subsano el error.

Disculpen el paréntesis. Creo que no es impertinente, pues nos va a permitir (al menos, a mí) mirar con benevolencia y comprender los errores en que también incurrió nuestro predecesor en el amor a la creación literaria de Lope de Vega y en el cuidado de su edición.

\section{Algunos errores de La Vega del Parnaso}

No faltan los desajustes en la príncipe de La vega del Parnaso. Señalaré solo un par de ejemplos.

Deseoso de que no se perdiera letra de las escritas por el genio, tras su muerte, Ortiz de Villena se apresuró a copiar en limpio uno de los poemas en que trabajaba cuando cayó enfermó: El siglo de oro. El manuscrito autógrafo, que no pasaría de un borrador, o una copia algo más legible, debió de incorporarse al legajo que se entregó a la imprenta sin pasar por la censura, ya que se trata de versos compuestos «cuando este cisne divino espiraba», ${ }^{20}$ y la aprobación de Valdivielso está datada el 26 de agosto, con la inserción de un breve paréntesis inmediatamente posterior en que da cuenta del tránsito del gran poeta.

20. Así se señala en la «Advertencia a los lectores» que precede al poema y se edita en el apéndice de este artículo. 
En estas circunstancias no puede sorprender que todos los editores de $E l$ siglo de oro se hayan tenido que enfrentar, con mayor o menor fortuna, a las incongruencias de varios pasajes del poema. Son bien conocidos los quebraderos de cabeza que han proporcionado los primeros versos. En La vega del Parnaso se lee:

\author{
Fábrica de la inmensa arquitectura \\ de este mundo inferior que el hombre imita, \\ pues como punto indivisible encierra \\ de su circunferencia la hermosura, \\ y copiose la tierra \\ de cuanto en ella habita \\ con tantos peregrinos ornamentos [...] (vv. 1-7)
}

El texto, ya por errores imputables a Ortiz de Villena, que parece haber preparado el manuscrito para la imprenta, ya por una mala lectura de los componedores, resulta ininteligible. Dejo al margen la errata copiose por copiosa, quizá inducida por el desajuste sintáctico del conjunto. $\mathrm{Y}$ vamos al primer verso, que ha ofrecido notable resistencia a los editores. Algunos (Cerdá y Rico en las Obras sueltas, 17761779, y Carreño, 2005) se resignaron a trascribir el texto deturpado. Quintana propuso la enmienda Fábrica fue de inmensa arquitectura. Cayetano Rossell corrigió Fábrica fue la inmensa arquitectura. Textos todos ellos insatisfactorios. Creo que la enmienda acertada es la que mis amigos y compañeros Pedro Conde Parrado y Cristina González Valencia incorporaron a la edición de 2015: «Fabricada la inmensa arquitectura».

Se trata, como comentaron en nota, de una construcción absoluta, con el valor de 'Una vez fabricada la inmensa arquitectura...', que se extiende a lo largo de los cuatro primeros versos y se yuxtapone a otras estructuras sintácticas similares que se dilatan hasta el v. 36 .

Otro error que ha pervivido hasta nuestros días es la ausencia del v. 67 de la canción A san Pedro Nolasco, que falta en el impreso de 1637, pero se ha podido rescatar gracias al Códice Daza, donde la estancia está completa.

En general, La vega del Parnaso deturpa levemente los versos de las ediciones sueltas, cuidadas directamente por Lope, que, en estos casos, relativos a sus poemas líricos (no los dramáticos), parece haber sido un corrector más diligente y afortunado que Ortiz de Villena. Así, el texto de la suelta de la égloga «Amarilis» (1633), pieza 
capital del poemario, es más correcto que el de La vega... Como los azares históricos han determinado que el único ejemplar conocido de la príncipe haya estado perdido durante años (véanse Profeti 2011, y Pedraza 2010), las lecturas erróneas se han perpetuado hasta tiempos muy recientes.

\section{LA RESURRECCIÓN DEL «FÉNIX DE ESPAÑA»}

Además de estas trascripciones defectuosas, bien por error de Ortiz de Villena en su papel de amanuense, bien por negligencia de los componedores, en teoría supervisados en pruebas por el licenciado, existen también alteraciones voluntarias, especialmente en los elementos que rodean los versos de Lope de Vega (lo que se ha dado en llamar paratextos).

Estas diferencias pueden observarse incluso en los libros que preparó en los últimos meses de su vida y que presentó personalmente para su censura y aprobación. Es el caso de la Parte XXI. El pliego de preliminares, compuesto e impreso con posterioridad al 5 de setiembre (fecha de la tasa), ya no pudo estar al cuidado del autor.

En el prólogo, escrito por Ortiz de Villena unos días después de la muerte del genio, se evidencia también el deseo de cumplir con su voluntad, no permitirse libertades frente a las decisiones que había tomado, y defender su prestigio intelectual:

Él quiso que este libro fuese la Veinte y una parte verdadera de sus comedias, que las demás que se han impreso en Sevilla, Zaragoza, Valencia y otras partes, todas son de diversos poetas y, aunque están a su nombre, no son suyas, que solo han servido de quitar la honra a sus escritos, y dar de comer a los libreros que las han impreso sin licencia.

En general, los datos de que disponemos nos llevan a pensar que, en efecto, los directos administradores de la herencia editorial de Lope de Vega trabajaron todo lo bien que sus alcances, conocimientos y circunstancias les permitían para trasladar al público la última voluntad del autor. Pero hoy podemos afirmar que no siempre acertaron a interpretarla.

En otro momento, he tenido la oportunidad de enfrentarme a una cuestión menor, pero que me parece significativa: el sobrenombre literario aplicado al poeta. En un artículo que se publicó en el homenaje a nuestro amigo y maestro Luis Igle- 
sias Feijoo, traté de evidenciar las razones por las que Lope no participó del entusiasmo que sintieron sus admiradores por las denominaciones encomiásticas de Fénix, Fénix de España o Fénix de los ingenios (véase Pedraza 2014b). Además de cierto pudor, del que no carecía el (en muchas cuestiones) descarado dramaturgo, el elogiosísimo mote quedó negativamente marcado en su conciencia por la utilización que hizo de él Francisco de Ávila. Con buen olfato comercial, el «mercader de paños», inversor y ocasional poeta lo usó como fórmula promocional al frente de las Partes VI (1615), VII (1616 y 1617) y VIII (1617). Las tres están encabezadas por el rótulo propagandístico:

EL FENIX | DE ESPAÑA | LOPE DE VEGA CAR | pio Familiar del Santo | Oficio, | SEXTA PARTE DE SVS COMEDIAS...

EL FENIX | DE ESPAÑA | LOPE DE VEGA | Carpio, Familiar del Santo | Oficio, | SEPTIMA PARTE DE SVS | Comedias. Con Loas, Entremeses, | y Bayles...

EL FENIX DE ESPAÑA | LOPE DE VEGA | Carpio, Familiar del Santo | Oficio. | octAVA PARTE DE SVS | Comedias. Con Loas, Entremeses, | y Bayles...

Sabemos que la idea de encabezar el título con el epíteto el Fénix de España es de Francisco de Ávila, ya que no se había usado antes en las ediciones de obras de Lope y figura en el privilegio, datado el 24 de diciembre de 1614, que se extendió a su nombre para la publicación de la Sexta parte (p. 57):

Por cuanto por parte de vos, Francisco Dávila, vecino de la villa de Madrid, nos fue hecha relación teníades un libro muy curioso intitulado El Fénix de España Lope de Vega Carpio en el cual iban doce comedias suyas muy ejemplares...

En cuanto el dramaturgo tomó las riendas de la edición de sus comedias, a partir de la Parte IX (1617), el rótulo encomiástico desapareció:

DOZE | COMEDIAS DE LOPE | DE VEGA, sacadas de | sus originales por el mismo. | dirigidas al excelentissi- | mo señor don Luys Fernandez de Cordoua y Aragon, Du- | que de Sesa [...]. | Novena PARTE. 
Así se mantiene hasta la Parte $X X$ (1627), última que vio impresa. Cuando aparece la Parte XXI, en setiembre de 1635 , ya muerto el poeta, el sobrenombre resucita del olvido a que lo había condenado. En los escasos días que median entre el 27 de agosto y los primeros días de setiembre, se imprime el cuadernillo de preliminares, al cuidado de Ortiz de Villena, que prologa el volumen; y en la portada leemos:

\footnotetext{
VEINTE Y VNA | PARTE | VERDADERA DE LAS | COMEDIAS DEL FENIX DE | España Frei Lope Felix de Vega Carpio, del Abito de San | Iuan, Familiar del Santo Oficio de la Inquisicion, | Procurador Fiscal de la Camara Apostolica, | sacadas de sus originales...
}

Los documentos oficiales registran, en cambio, el título con el que Lope presentó por segunda vez al consejo de Castilla la nueva colección en los primeros meses de 1635. Especialmente claro queda este punto en la suma de la tasa y en la fe de erratas, donde se designa al volumen como Veinte y una parte de las comedias de frey Lope Félix de Vega Carpio.

Creo que no cabe la menor duda: Ortiz de Villena añadió por su cuenta y riesgo lo de el Fénix de España. Es posible que no se hubiera percatado del disgusto que sentía Lope de Vega ante este sintagma, probablemente recordando el malhadado pleito que sostuvo con Francisco de Ávila; pero no es descartable que atribuyera su ausencia en las Partes precedentes (de la $I X$ a la $X X$ ) a la modestia del poeta.

Tanto la Parte XXII como La vega del Parnaso ostentarán el conflictivo rótulo, de acuerdo con el uso habitual de las partes extravagantes, como la publicada en Valencia, en 1629, con el título de

EL FENIX DE ESPAÑA | LOPE DE VEGA CARPIO | VEINTE Y TRES PARTE DE SUS | COMEDIAS, | Y LA MEJOR PARTE QUE HASTA OY | SE HA ESCRITO. | Año [dibujo] 1629. | CON LICENCIA. | En Valencia, por Miguel Sorolla, junto a la Vniversidad. | A costa de Luys de Soto Velasco vezino de Seuilla. ${ }^{21}$

La costumbre se mantuvo en las colecciones posteriores (Partes XXIII, XXIV y $X X V$ ), publicadas en Zaragoza. Sin embargo, la referencia al fénix desapareció en la Parte XXIII (Madrid, 1638), preparada por Faria y Sousa, quizá mejor informado

21. Tomo la descripción de la portada de Hernández Gónzález [1992:180]. 
que Ortiz de Villena del disgusto del poeta con el mote que se ha acabado perpetuando a lo largo de los siglos:

PARTE | VEINTE Y TRES | DE | COMEDIAS DE LOPE | FELIX DE VEGA CARPIO, | DEL ABITO DE SAN PEDRO | y DE S. Ivan. [...] | Año [Escudo de don Gutierre Domingo de Terán.] 1638 | Con Priuilegio. En Madrid. Por Maria de Quiñones. | A costa de Pedro Coello Mercader de Libros.

\section{LAS DEDICATORIAS}

Es bien conocido el interés que tuvo el poeta en controlar las ediciones y, con ellas, las dedicatorias de sus obras. Ninguno de sus libros salió sin llevar estampado el nombre del dedicatario o dedicataria (el número de mujeres es bastante crecido). Desde los inicios de su carrera de publicista: Arcadia (1598), al duque de Osuna; Isidro (1599), al ayuntamiento de Madrid; La hermosura de Angélica (1602), a don Juan de Arguijo...

Siempre dio una singular importancia a estos escritos e incluso teorizó repetidamente sobre las razones que lo llevaban a redactarlos. En la dedicatoria de $E l$ hombre por su palabra al licenciado Diego de Molino y Avellaneda dice:

Tres cosas inclinan a los que escriben a dirigir sus obras: obligación a las personas de quien hacen elección, favor que esperan, o ser tan insignes en lo que profesan que de justicia se les debe alabanza y reconocimiento... (Lope de Vega, Las dedicatorias, p. 251)

Como es sabido, cuando en 1614 consigue publicar la Parte IV, gracias a los manuscritos que le facilita Gaspar de Porres, la dedica al duque de Sessa. Es posible que, incluso antes de recuperar el control de las ediciones, en medio de los pleitos y disgustos con Francisco de Ávila, no fuera ajeno a la decisión del librero Miguel de Siles de dirigir las Partes VII y VIII a don Luis Fernández de Córdoba.

Después de la Parte IX (1617), que sale de la casa del poeta, aunque no siempre «sacada de sus originales» (recuérdese el apaño que tuvo que hacer para incluir La dama boba), ${ }^{22}$ prosigue su política dedicatoria a personalidades de relieve social:

22. Véanse los estudios de Dixon [1997], Profeti [1996] y Presotto [2007:1297-1319], que divergen en algunas de sus conclusiones. 
el duque de Sessa, en primer lugar (Parte IX, 1617), el marqués de Santa Cruz (Parte $X, 1618$ ), Bernabé de Vivanco y Velasco (Parte XI, 1618) y don Lorenzo de Cárdenas, conde de la Puebla (Parte XII, 1619).

Como es sabido, en la portada de la Parte XIII (1620) se anuncia un cambio en la fórmula: las comedias están «dirigidas, cada una de por sí, a diferentes personas». La multiplicidad de dedicatorias dentro de un mismo libro no era enteramente nueva en Lope. La edición independiente de las Rimas (Sevilla, 1604) está dirigida, en la portada y el cuadernillo preliminar, a don Juan de Arguijo; pero la Segunda parte, que veía la luz por vez primera, se ofrece particularmente a doña Ángela Vernegali, dama sevillana. La única diferencia respecto a la Parte XIII es cuantitativa: las dos dedicatorias del poemario, que se mantendrán en todas las ediciones que dependieron del poeta, se convierten en doce.

Este expediente se usará en todas las Partes que estuvieron a su cuidado: hasta la $X X$ (1627). Sin duda, Lope gustaba de estas dedicatorias múltiples que le permitían atender a sus numerosas relaciones sociales. Frente a las críticas que surgieron, defendió su inalienable derecho a actuar de esta manera:

En esta Parte $X X$ tiene vuestra merced doce comedias dirigidas a diferentes personas, como he tenido gusto de presentarlas; que hasta en esto hay quien censure voluntades, rescinda obligaciones y mande en casa ajena (Lope de Vega, Las dedicatorias, p. 234).

Cabría esperar que este formato, del que parece estar tan orgulloso en 1627, siguiera vivo en la Parte $X X I$ y en la XXII, que aparecieron póstumas pero debieron de ser preparadas por el poeta, que solicitó por dos veces (1626 y 1635) permiso para imprimirlas.

Pero no es así. La Parte XXI tiene una dedicataria única: doña Elena Damiana de Iuren Sámano y Sotomayor, mujer del señor de Tielmes y embajador de Lorena. Lo mismo ocurre con la Parte XXII, dirigida a la marquesa de Cañete. En los dos casos, las dedicatorias se escribieron tras la muerte del poeta y las firman su hija Feliciana y su yerno Luis de Usátegui, a pesar de que ambas estaban aprobadas y entregadas a la imprenta en los primeros días del verano de 1635, cuando el poeta seguía activo y estaba ocupado, entre otras cosas, en el proceso de edición de estos tomos y en la preparación de La vega del Parnaso. 
¿Qué pudo ocurrir? ¿En agosto de 1635 Lope había perdido «el gusto de presentar» sus comedias dirigidas a diversas personas, y en consecuencia, ni había decidido a quién consagrarlas ni había redactado las cartas dedicatorias? ¿Cuándo pensaba hacerlo?

Quizá la ejecución de estos propósitos se retrasaba en algunos casos hasta que el libro estaba a punto de salir al mercado. En la Parte XXIII, Faria y Sousa nos dejó testimonio de lo tarde que, a veces, se tomaban estas decisiones:

Hallándose Pedro Coello, mercader de libros en esta corte, al fin de la impresión de esta Parte XXIII de las comedias del siempre admirable Lope, dejó a mi elección la dedicatoria de ellas, fiando de la amistad que en mí conoce y del conocimiento que tengo de personas capaces, que le emplearía bien (Lope de Vega, Parte XXIII, preliminares, f. 4, s.n.).

En la Parte XXI (preliminares, f. 2, s.n.), Feliciana sostiene que, al dirigir el volumen a doña Elena Damiana, no hace más que cumplir la voluntad de su padre:

Yo, que con su sangre heredé sus afectos y sus obligaciones, por lisonjear su pretensión y honrar sus versos, se los dedico a vuestra señoría. No digo bien, que él se los dedica, porque, aunque muerto, vive en mi alma. Vuestra señoría las reciba, si no de su mano, de mano de un pedazo de su corazón, que todo le consagra a su servicio.

Con la humildad tópica en este tipo de escritos, subraya la distancia entre la brillante y erudita dedicatoria que hubiera compuesto su padre y la sencilla y modesta que ella es capaz de pergeñar:

Aquí dijera aquel ingenio grande muchas alabanzas de la ascendencia ilustrísima de vuestra señoría de los condes de Iuren en Alemania, de su antigüedad, de su virtud y su generosidad. Él, que supiera, lo pudiera decir. Yo, que no puedo con su elocuencia y elegancia, las remito al silencio, por no dislustar el decoro de su grandeza y ofender la modestia grande de vuestra señoría, a quien suplico honre sus afectos y favorezca mis deseos (Lope de Vega, Parte XXI, preliminares, f. 2, s.n.).

En la carta a doña Catalina de Zúñiga y Avellaneda, marquesa de Cañete, de la Parte XXII, Luis de Usátegui también subraya que le dirige el conjunto de las doce comedias: 
solicitado de la voluntad que reconocí tenía [Lope de Vega] de dedicárselas a vuestra excelencia antes de pasar de esta vida mortal a la que goza, en reconocimiento de las infinitas mercedes que recibió de su ilustrísima casa (Lope de Vega, Parte XXII, preliminares, f. 2, s.n.).

Tanto el texto de Feliciana como el de Luis de Usátegui se tuvieron que escribir muy poco después (quince, veinte días) de morir Lope. ¿Estaba el poeta arrepentido de tanta dedicatoria como había acumulado en las partes precedentes? Es posible. Pero me inclino más bien a creer que el cortar con este hábito es una determinación de sus albaceas literarios, que no sentían la misma necesidad de sostener ese entramado de relaciones sociales.

En La vega del Parnaso, que se compuso a partir de ejemplares de las sueltas, se suprimieron todas las dedicatorias particulares y quedó solo la general del volumen al duque de Sessa, firmada por Luis de Usátegui, «en reconocimiento de las muchas obligaciones que yo y mi familia tenemos a vuestra excelencia» (Lope de Vega, La vega del Parnaso, preliminares, f. 4, s.n.). Lo más probable es que la decisión la tomara Ortiz de Villena, que, según todos los indicios, cuidó de la recogida de los ejemplares (impresos y manuscritos) que acabarían configurando el volumen, y de la estampa.

En razón de este expediente, cayeron las muy pensadas dedicatorias a Felipe IV (Elogio en la muerte de Juan Blas de Castro), a Ana de Austria («Amarilis»), a Fernando de Austria (Canción de la Congregación de Sacerdotes..., que hemos recuperado en este artículo), a Lorenzo Ramírez de Prado («A Claudio»), a Luis Méndez de Haro («Huerto deshecho») y a Bernarda Ferreira de la Cerda (Filis), además de aquellas otras de las que no poseemos original porque no conservamos las ediciones sueltas — que, presumiblemente, salieron a la luz en un reducido número de ejemplares- ni figuran en los borradores manuscritos de estas fechas: Daza, Pidal y Durán. ¿Hubieran desaparecido estos escritos si Lope hubiera estado al cuidado de la edición? Mi opinión quedó expresada hace unos años:

Quizá en la primavera de 1635 Lope estuviera lo bastante desengañado como para prescindir de estos párrafos gratulatorios; pero es más fácil suponer que Ortiz de Villena, que no tenía por qué sentir ese gusto ni se veía impelido por obligación alguna, juzgara que el volumen quedaba más limpio con esas supresiones. Además, así podía brillar sin competencia el mecenas al que se consagraba el conjunto de la obra (Pedraza 2014a:32). 
En este punto, como en otros, podemos concluir que los responsables de las ediciones póstumas (entre ellos, Ortiz de Villena) quisieron ser fieles al autor en lo esencial, pero no tanto como para mimetizar sus gustos, usos y costumbres.

\section{FIESTAS DEL SANTíSIMo SACRAMENTo (1644)}

Quizá la iniciativa más personal y más original de Ortiz de Villena fue la publicación de las Fiestas del Santísimo Sacramento, un volumen con doce autos sacramentales, acompañados de las loas y entremeses que completaron las representaciones callejeras de los mismos.

Fue una empresa, en cierta medida, pionera, ya que probablemente es la primera colección de autos sacramentales sin mezcla de elementos ajenos a las celebraciones eucarísticas. Es verdad que Lope inició su carrera de publicista dramático con la inclusión de cuatro piezas en la trama novelesca de $E l$ peregrino en su patria (1604), que Montalbán incorporó también obras alegóricas en Para todos (1632) y Tirso, en Deleitar aprovechando (1635). Valdivielso dio un paso adelante cuando sacó a la luz Doce autos sacramentales y dos comedias divinas (1622). Prescindió de la argamasa narrativa, pero no se resistió a añadir dos comedias de santos, quizá como cebo para los posibles compradores (véase Gómez Sánchez-Ferrer 2015:50). Todo indica que dramaturgos y libreros sentían un justificado vértigo económico y reputacional, como se dice ahora, ante la perspectiva de ofrecer al público los textos representados en las fiestas del Corpus, sin ningún otro aditamento. Germán Vega puntualizó con claridad meridiana las razones de esta resistencia:

Autos sacramentales y piezas breves no tienen esta capacidad [de las comedias] de atraer a los lectores. Los primeros, que basan una parte importante de su eficacia artística en la espectacularidad de la puesta en escena, imposible de reflejar en el papel, no ofrecen historias verosímiles. ${ }^{23}$

El mismo Lope, que tanto luchó para ver impresas sus comedias, renunció a la

23. Vega García-Luengos [2010:68]. Véase también, del mismo investigador, el capítulo «Piezas breves en ediciones que intentan reflejar la fiesta teatral barroca» (Vega García-Luengos 2014:526-529). 
posibilidad de lanzar al mercado partes de sus autos. Rodríguez Ortega [2018:163] ha señalado las razones de esta determinación:

En el momento de la lectura faltaban los pasacalles, las tarascas, el desfile de autoridades, la custodia, etc., pero también el sentido de comunidad de la celebración de uno de los días más importantes en el calendario cristiano.

Sin embargo, Ortiz de Villena, consagrado a perpetuar la memoria de Lope y a difundir su obra, no quiso que esta parcela quedara en el olvido, y rescató un ramillete de fiestas sacramentales de los centenares que sus contemporáneos atribuyen al Fénix. ${ }^{24}$ Aunque apela a la tópica insistencia de los aficionados para dar a la luz el libro, no deja de manifestar que se trata de una iniciativa exclusivamente suya:

muchos días ha que he deseado sacar a luz algunos autos sacramentales que aquel Fénix de España con tanta erudición escribió, y importunado de amigos, he dado a la estampa este libro, a quien intitulo Fiestas del Santísimo Sacramento...

Obsérvese la inusual presencia de la primera persona (incluso a la hora de dar título al libro), que contrasta con el escrito similar al frente de la Parte XXI, que ya hemos citado: «Él [Lope] quiso que este libro fuese la Veinte y una parte verdadera de sus comedias...».

Es posible, como sugiere Gómez Sánchez-Ferrer [2015:500-502], que el modelo para la recopilación fuera el libro de Valdivielso: el mismo número de autos (probablemente inspirado en las partes de comedias) y una impresión realizada fuera de la corte: Toledo en 1622, Zaragoza en 1644.

La labor de Ortiz de Villena debió de ser doble: la ya conocida de reunir los manuscritos, y la nueva de negociar con el librero Pedro Vergés, sin la intervención ni la tutela de Luis de Usátegui que vimos en los demás libros. Quizá estas circunstancias expliquen que el volumen se imprimiera en Zaragoza, en los talleres del homónimo y

24. Pérez de Montalbán (Fama póstuma, p. 31) apunta hiperbólicamente que «los autos sacramentales pasan de cuatrocientos», y Juan Antonio de la Peña le atribuye «más de doscientos» en el prólogo Al lector, de su opúsculo A la fama inmortal del Fénix de Europa [f. 5]. El GRISO, de la Universidad de Navarra, ha emprendido en los últimos años la edición crítica de los autos de Lope de Vega, dirigida por Ignacio Arellano y coordinada por Enrique Duarte, de la que han aparecido 6 volúmenes (Reichenberger, Kassel, 2017-2020) con doce piezas, preparadas por prestigiosos hispanistas como el mismo Enrique Duarte, José Manuel Escudero, Victoriano Roncero, Ignacio Arellano-Torres, Elena E. Marcello, Fernando Rodríguez-Gallego, Daniele Crivellari y Alejandra Ulla. 
quizá pariente del empresario editor que tenía su librería en la madrileña calle de Toledo. Además, se hizo una tirada para el librero aragonés Pedro Alfay.

Dos autos de los que se incluyen en el volumen han visto discutida su autoría: Los acreedores del hombre y El pastor lobo. Ante estas dudas, Barrera ya salió en defensa de la probidad de Ortiz de Villena:

No puede creerse, atendido su respetable carácter, que de intento mezclase en esta publicación obras de otros autores, ni menos que diese a luz entre ellas algunas de su pluma propia (Barrera 1860:458).

Los acreedores del hombre se ha atribuido a Rojas Zorrilla. El mismo título encabeza el manuscrito de un auto conservado en la Biblioteca Nacional de España (MS/15168/2); pero se trata de obras enteramente distintas, tal y como señalaron Urzáiz [2002:II, 684] y Cienfuegos [2015:83]. Parece, no obstante, que entre las dos hay una clara filiación: coinciden parte del dramatis personae (el Hombre, el Tiempo, la Justicia, la Tierra, el Pecado) y algunas de las situaciones; pero en lo que se refiere a los versos y al desarrollo dramático, son independientes.

El pastor lobo se ha atribuido a Mira de Amescua y se ha incluido en la edición del Teatro completo del dramaturgo accitano, ${ }^{25}$ pero no conozco razones que avalen esta hipótesis, fuera de la aparición tardía en catálogos de Medel o García de la Huerta... (véase Valladares 2004:132).

Más dudas presentan los entremeses. Dos de ellos (El remediador y Los órganos) se tienen por obra de Luis Quiñones de Benavente (el primero se incluyó en Jocoseria, 1645, promovida por el autor) y otros se publicaron anónimos en diversas colecciones. Quizá haya que entender que tanto estas piezas breves como las loas acompañaron en la representación a los autos de Lope, aunque no fueran de su autoría. Es posible que Ortiz de Villena insinúe estos hechos en las palabras que dirige $A$ los aficionados de frey Lope Félix de Vega Carpio:

cada uno [cada auto] con su loa y su entremés, para que se hallen hechas las fiestas en los lugares como se representaron en esta corte.

25. Mira de Amescua, El pastor lobo y cabaña celestial [2007]. En los rótulos superiores de las páginas pares se indica, con prudencia: «Lope de Vega o Mira de Amescua». 
Es decir: a los autos de Lope han añadido las loas y entremeses con que se representaron en Madrid, sean o no de su autoría, para que en los pueblos puedan reproducirse las fiestas con el mismo esplendor que en la capital.

La colección tiene el particular interés de haber salvado una parte relevante del elenco de los autos sacramentales de Lope.

\section{Conclusiones}

Con las irregularidades inevitables en los procesos de edición (no olvidemos nunca la traviesa e impredecible actividad de los duendes de imprenta), la obra de Ortiz de Villena merece un particular reconocimiento. Gracias a él, las generaciones sucesivas hemos podido acceder sin mayores dificultades a una serie de comedias del mayor interés, entre las que se cuenta una obra maestra del genio de Lope: $E l$ castigo sin venganza. El testimonio del que partieron los editores decimonónicos para la fijación del texto fue el de la Parte XXI. Lo mismo ocurre con los excepcionales poemas de La vega del Parnaso («Amarilis», «A Claudio», «Huerto deshecho»...), de los que se han conservado contados ejemplares de las sueltas (en el caso de «Amarilis», uno solo, que, además, anduvo perdido durante cincuenta años). Lo mismo ocurre con los autos sacramentales, rescatados del olvido por el empeño y la amistad del sacerdote amigo y compañero en la Congregación de San Pedro. De otras varias comedias y poemas no tenemos más testimonio próximo al autor que el que nos ha llegado gracias a la tarea editorial de Ortiz de Villena.

En la medida que hoy se conocen, podemos afirmar que, en general, se trata de testimonios razonablemente correctos, aunque inferiores a sus fuentes. No faltan en ellos algunos errores y erratas, y ciertos cambios en los paratextos que, según todos los indicios, el autor no hubiera introducido. Pero, en la historia de la conservación y difusión de nuestro patrimonio cultural, el trabajo, honesto y generalmente acertado de Ortiz de Villena ha sido capital. Ahora, en circunstancias distintas, con medios y técnicas que no estaban al alcance del venerable sacerdote, tenemos la oportunidad de mejorar los textos que nos legó. $\mathrm{O}$, al menos, intentarlo. 


\section{BIBLIOGRAFÍA}

Álvarez de Baena, José Antonio, Hijos ilustres de Madrid en santidad, dignidades, armas, ciencias y artes, Benito Cano, Madrid, 1789-1791, 4 vols.; facsímil en Atlas, Madrid, 1973.

BarRedA, Francisco, «Invectiva a las comedias que prohibió Trajano y apología por las nuestras», en El mejor príncipe, Trajano Augusto. Su filosofía política, moral y económica, deducida y traducida del «Panegírico» de Plinio, ilustrado con márgenes y discursos, Viuda de Cosme Delgado, Madrid, 1622, ff. 120v-141v.

BARRERA, Cayetano Alberto de la, Catálogo bibliográfico y biográfico del teatro antiguo español desde sus orígenes hasta mediados del s. XVIII, Rivadeneyra, Madrid, 1860; facsímil en Gredos, Madrid, 1969.

Barrera, Cayetano Alberto de la, Nueva biografía de Lope de Vega, Atlas («Biblioteca de autores españoles»), Madrid, 1973-1974; primera ed. Obras de Lope de Vega, Real Academia Española, Madrid, 1892. La obra, con el título de Crónica biográfica y bibliográfica de Lope de Vega, estaba acabada en 1864. BlEcuA, José Manuel, Introducción, edición y notas de Lope de Vega, La Dorotea, Ediciones de la Universidad de Puerto Rico-Revista de Occidente, Madrid, 1956; nueva ed. Cátedra, Madrid, 1996.

Bouza Álvarez, Fernando, «Política del libro del Consejo Real en tiempo de Olivares», en Poder y saber: bibliotecas y bibliofilia en la época del conde-duque de Olivares, intr. J. Elliott; dir. O. Noble Wood, J. Roe y J. Lawrence, Centro de Estudios Europa Hispánica, Madrid, 2011, pp. 339-362.

Capmany y Montpalau, Antonio de, Museo histórico que comprende los principales sucesos de España y el extranjero como asimismo toda la parte artística y monumental de los principales países, Imprenta de Cristóbal González, Madrid, 1862² 2 tomos. Cardoso, Fernando, Oración fúnebre en la muerte de Lope de Vega Carpio, ingenio laureado de las Musas, prodigiosa maravilla de España, eterna admiración de las edades, en Lope de Vega, Obras sueltas, Antonio de Sancha, Madrid, 1778, tomo XIX, pp. 467-492.

Cienfuegos Antelo, Gema, «Los autos sacramentales de Rojas Zorrilla: consideraciones acerca del repertorio y su representación», en El universo dramático de Rojas Zorrilla, ed. R. González Cañal, Universidad de Valladolid, Valladolid, 2015, pp.79-90. 
Conde Parrado, Pedro, y Cristina Gutiérrez Valencia, estudio, edición y notas de $E l$ siglo de oro, en La vega del Parnaso de Lope de Vega, ed. Instituto Almagro de teatro clásico, dirs. F.B. Pedraza Jiménez y P. Conde Parrado, Universidad de Castilla-La Mancha, Cuenca, 2015, vol. 1, pp. 77-108.

Dixon, Victor, «El auténtico Antonio Roca de Lope», en Homenaje a William L. Fichter. Estudios sobre el teatro antiguo hispánico y otros ensayos, ed. A.D. Kossoff y J. Amor Vázquez, Castalia, Madrid, 1971, pp. 175-188.

Gómez SÁnchez-Ferrer, Guillermo, Del corral al papel: estudio de impresores españoles de teatro en el siglo XVII, tesis doctoral dirigida por J. Huerta Calvo y A. Madroñal Durán, Universidad Complutense de Madrid, Madrid, 2015.

Hernández GonzÁlez, Erasmo, «Una desconocida parte de comedias de Lope (Parte XXIII, Valencia, 1629)», Criticón, LVI (1992), pp. 179-186.

Mayor Gimeno, Vicente, Historia de la Venerable e Ilustre Congregación de San Pedro Apóstol de Presbiteros Seculares Naturales de Madrid, y sus relaciones con La Mutual del Clero Español, Imprenta Avilista, Madrid, 1964.

McGrady, Donald, ed., Lope de Vega, Antonio Roca, Juan de la Cuesta, Delaware, 2009. Mesonero Romanos, Ramón de, «Catálogo cronológico de autores dramáticos, y alfabético de las comedias de cada uno», en Dramáticos posteriores a Lope de Vega. I, Rivadeneyra, Madrid, 1858, pp. xxxvii-liii.

Mira de Amescua, Antonio, El pastor lobo y cabaña celestial, ed. M. Fernández Labrado, en Teatro completo, VII, dir. A. de la Granja, Universidad de Granada, Granada, 2007, pp. 859-900.

Pedraza Jiménez, Felipe B., «Prólogo» al facsímil de Lope de Vega, La vega del Parnaso, Ara Iovis, Madrid, 1993, pp. vii-xvi.

Pedraza Jiménez, Felipe B., Los duendes de imprenta, en el Mercurio Ministerial, Lecciones para no salir de dudas. Segundas partes, El caduceo Ediciones, Madrid, 2004, pp. 113-118.

Pedraza Jiménez, Felipe B., «El desengaño barroco en las Rimas de Tomé de Burguillos», en Lope de Vega, genio y figura, Universidad de Granada, Granada, 2008, pp. 159-197; primera ed. Anuario de Filología, IV (1978), pp. 391-418.

Pedraza JimÉnez, Felipe B., «"Pues sabed que es el alma de mi pecho...” Una elegía íntima», prólogo al facsímil de Lope de Vega, Amarilis. Égloga, Fundación Caja Castilla La Mancha-Universidad de Castilla-La Mancha-GRISO-Universidad de Navarra, Madrid, 2010, pp. 9-86. 
Pedraza Jiménez, Felipe B., «La vega del Parnaso de Lope. La estructura que quiso ser y no fue», en Lope sin fronteras, ed. F. Raynié, Criticón, CXXII (2014a), pp. 27-40. Pedraza Jiménez, Felipe B., «Fénix, génesis de un sobrenombre», en «Diferentes» $y$ «Escogidas». Homenaje al profesor Luis Iglesias Feijoo, ed. S. Fernández Mosquera, Iberoamericana-Vervuert, Madrid-Frankfurt am Main, 2014b, pp. 393-410.

Pedraza Jiménez, Felipe B., «Introducción» a Lope de Vega, La vega del Parnaso, ed. Instituto Almagro de teatro clásico, dirs. F.B. Pedraza Jiménez y P. Conde Parrado, Universidad de Castilla-La Mancha, Cuenca, 2015, vol. 1, pp. 19-59.

Pedraza Jiménez, Felipe B., «Lope y sus actores», en La fuerza del amor y de la historia. Ensayos sobre el teatro de Lope de Vega, Universidad de Castilla-La Mancha, Cuenca, 2018, pp. 155-174; primera ed. en Texto y actor en el teatro áureo, eds. W. Aichinger, P. Casariego, S. Kroll y A. Vara López, Verlag Turia-Kant, Wien-Berlin, 2016, pp. 66-97.

Peña, Juan Antonio de la, A la fama inmortal del Fénix de Europa, fray Lope Félix de Vega Carpio, del hábito de San Juan, natural de Madrid, égloga elegiaca, s.i., Madrid, 1635; se reprodujo en Lope de Vega, Obras sueltas, Antonio de Sancha, Madrid, 1778, tomo XIX, pp. 493-520.

Peña López, Carlos, «Cartas de Belardo a Lucilo. Aproximación a la colección de cartas autógrafas de Lope y a sus vicisitudes históricas», Criticón, CXLII (2021), pp. 131-152.

Pérez de Montalbán, Juan, Fama póstuma a la vida y muerte del doctor frey Lope Félix de Vega Carpio..., ed. E. Di Pastena, ETS, Pisa, 2001.

Pérez de Montalbán, Juan, Para todos, en Obra no dramática, ed. J.E. Laplana Gil, Fundación Castro, Madrid, 1999, pp. 461-889.

Presotto, Marco, Le commedie autografe di Lope de Vega. Catalogo e studio, Reichenberger, Kassel, 2000.

Presotto, Marco, «Prólogo» a Lope de Vega, La dama boba, en Comedias de Lope de Vega. Parte IX, coord. M. Presotto, Milenio-Universitat Autònoma de Barcelona, Lérida-Bellaterra, 2007, vol. 3, pp. 1295-1323.

Profeti, Maria Grazia, «La Vega di Lope», en Varia hispanica. Homenaje a Alberto Porqueras Mayo, Reichenberger, Kassel, 1989, pp. 443-453.

Profeti, Maria Grazia, «Editar el teatro del Fénix de los ingenios», Anuario Lope de Vega, II (1996), pp. 129-151. 
Profeti, Maria Grazia, «Introduzione» a Lope de Vega, Comedias della «Vega del Parnaso». I. El guante de doña Blanca, ed. M.G. Profeti, Alinea, Firenze, 2006, pp. 7-46. Profetr, Maria Grazia, «Amarilis. 1633: una stampa "perduta” di Lope de Vega», en Ogni onda si rinnova. Studi di spanistica offerti a Giovanni Caravaggi, eds. A. Baldisera, G. Mazzochi y P. Pintacuda, Ibis, Pavia, 2011, pp. 381-390.

Rodríguez Ortega, Davinia, «Publicación de autos sacramentales en el siglo xvi: volúmenes propios, colectivos y misceláneas», Revista de Filología Española, XCVIII 1 (2018), pp. 161-184.

RozAS, Juan Manuel, Lope de Vega y Felipe IV en el «ciclo "de senectute"», Universidad de Extremadura, Cáceres, 1982; nueva ed. en Estudios sobre Lope de Vega, ed. J. Cañas Murillo, Cátedra, Madrid, 1990, pp. 73-132.

SERÉS, Guillermo, «A mis soledades voy...”: fuentes remotas y motivos principales», Anuario Lope de Vega, IV (1998), pp. 327-337.

URzÁiz, Héctor, Catálogo de autores teatrales del siglo xVII, Fundación Universitaria Española, Madrid, 2002, 2 tomos.

Valladares Reguero, Aurelio, Bibliografía de Antonio Mira de Amescua, Reichenberger, Kassel, 2004.

Vega Carpio, Lope de, 27 documentos de... en el Archivo de Protocolos de Madrid, introd. y trascripciones C. Davis, Comunidad de Madrid, Madrid, 2004.

Vega Carpio, Lope de, Comedias de Lope de Vega. Parte VI, coords. L. Giuliani y V. Pineda, Milenio-Universitat Autònoma de Barcelona, Lérida-Bellaterra, 2005. Vega CarPIo, Lope de, Las dedicatorias de Partes XIII-XX de Lope de Vega, ed. T.E. Case, University of North Carolina (Estudios de Hispanófila)-Castalia, Urbana-Madrid, 1975.

Vega Carpio, Lope de, La Dorotea, ed. J.M. Blecua, Ediciones de la Universidad de Puerto Rico-Revista de Occidente, Madrid, 1956; nueva ed. Cátedra, Madrid, 1996.

Vega Carpio, Lope de, Epistolario, ed. A. G[onzález] de Amezúa, Real Academia Española, Madrid, 1935-1943, 4 tomos; facsímil en Real Academia Española, Madrid, 1989.

Vega CARPio, Lope de, Laurel de Apolo, ed. C. Giaffreda, intr. M.G. Profeti, Alinea, Firenze, 2002.

Vega CARPIO, Lope de, Parte veinte y tres de comedias..., María de Quiñones, a costa de Pedro Coello, Madrid, 1638. 
Vega CARpio, Lope de, La vega del Parnaso, ed. Instituto Almagro de teatro clásico, dirs. F.B. Pedraza Jiménez y P. Conde Parrado, Universidad de Castilla-La Mancha, Cuenca, 2015, 3 vols.

Vega García-Luengos, Germán, «Sobre la identidad de las partes de comedias», Criticón, CVIII (2010), pp. 57-78.

VEGA GARCíA-LuEngos, Germán, «El teatro breve en la imprenta del siglo XvII: piezas publicadas en partes de comedias y autos», en «Diferentes» $y$ «Escogidas». Homenaje al profesor Luis Iglesias Feijoo, ed. S. Fernández Mosquera, Iberoamericana-Vervuert, Madrid-Frankfurt am Main, 2014, pp. 517-531. 


\section{APÉNDICE: DOCUMENTOS Y ESCRITOS DE JOSÉ ORTIZ DE VILLENA}

NORMAS DE EDICIÓN: Como es habitual en las ediciones de textos del siglo xviI, en esta edición respeto escrupulosamente los rasgos lingüísticos del autor; pero modernizo la ortografía en todo lo que, presumiblemente, carece de valor fonológico; desarrollo las abreviaturas; deshago las contracciones hoy en desuso; regularizo el empleo de mayúsculas y minúsculas según los criterios actuales, y puntúo y distribuyo en párrafos según mi interpretación.

Quedan al margen de estas normas la descripción de las portadas de los distintos testimonios.

$1 \mathbf{1 6 2 5}$
[Acta de ingreso
en la Congregación de San Pedro
DE Sacerdotes Naturales de Madrid]
Libro 1 de Entradas de congregantes-Folio 39R
$\dagger \quad$ Mayo 13 de $1625 \quad \dagger$

Presbítero

Josef Ortiz

de Villena, núm. 92

En la villa de Madrid, a trece días del mes de mayo de mil y seiscientos y veinte y cinco años, estando juntos y congregados en la iglesia parroquial del señor San Miguel de los Octoes, en junta particular de mes, según costumbre, el señor licenciado Eugenio de Bustamante, capellán mayor, y consiliarios, con otros oficiales y congregantes de la Venerable Congregación del Señor San Pedro, sita al presente por autoridad de ordinaria en la dicha iglesia, para tratar y difinir las cosas tocantes al augmento y gobierno de la dicha Congregación, con acuerdo de todos, se admitió y recibió por congregante al licenciado Josef Ortiz de Villena, presbítero natural de Madrid, como constó por sus títulos, el cual juró de guardar y tener la Limpia Concepción de 
Nuestra Señora, y decir dos misas cada mes para los gastos de ella, y lo firmó. E yo, el infraescrito secretario, me hallé presente y lo firmé el dicho día, mes y año.

[Firmas y rúbricas]

El licenciado Eugenio de Bustamante

El licenciado Josef Ortiz de Villena

\author{
Ante mí, \\ el maestro Francisco Pérez, \\ secretario.
}

$\mathrm{N}^{\circ} 92$

[Una anotación posterior en la parte superior del margen izquierdo:]

Murió.

Requiescat in pace.

\title{
1635
}

VEINTE Y VNA | PARTE | VERDADERA DE LAS | COMEDIAS DEL FENIX DE | España Frei Lope Felix de Vega Carpio, del Abito de San | Iuan, Familiar del Santo Oficio de la Inquisicion, | Procurador Fiscal de la Camara Apostolica, | sacadas de sus originales. | [...] | Año [Florón.] 1635. | CON PRIVILEGIO. | [Filete.] | En Madrid, Por la viuda de Alonso Martin. | A costa de Diego Logroño, mercader de libros. | Vendese en sus casas, en la calle Real de las Descalzas.

[Preliminares, f. 6r, s.n.]

El licenciado Josef Ortiz de Villena

A los aficionados de Frey Lope FéLIX de VeGa CARPIO

El doctísimo Séneca y Pitágoras refieren que el valeroso rey de los epirotas, Pirro, queriendo dejar en su reino una cosa memorable, buscó aquella preciosísima piedra Acates, la cual (como cuenta Plinio, y refiere Bartolomé Cassaneo) tenía esculpidas 
las nueve Musas (que son las ciencias) con sus cetros y demás insignias e instrumentos, y en medio al dios Apolo tocando su cítara; y así, se glorió y tuvo por muy dichoso el rey de tener tan inestimable piedra en su poder, la cual dejó en vínculo y mayorazgo a todos los reyes sus sucesores. ${ }^{26}$

Con mayores ventajas debo yo estimar las obras del eminentísimo varón frey Lope Félix de Vega Carpio, pues habiendo juntado en mi poder la mayor parte de sus obras (que me costó no pequeño trabajo), cada una es piedra Acates de inestimable valor, pues en ellas se hallarán ${ }^{27}$ en la dulzura de sus versos las ciencias de las Musas; con tantas agudezas y primores, la lira de Apolo, de quien todos pueden gozar y sacar los quilates de piedra de tanta estima.

A persuasión suya, le di estas doce comedias, sacadas de sus borradores y originales, para darlas a la estampa. Él quiso que este libro fuese la Veinte y una parte verdadera de sus comedias, que las demás que se han impreso en Sevilla, Zaragoza, Valencia y otras partes, todas son de diversos poetas y, aunque están con su nombre, no son suyas, que solo han servido de quitar la honra a sus escritos, y dar de comer a los libreros que las han impreso sin licencia.

Después de estas, saldrá también la Parte veinte y dos verdadera, y luego ofrezco La vega del Parnaso, con otras comedias y varias rimas, donde se hallará lo mejor que él escribió en toda su vida, que, aunque el cielo fue servido de quitársela, como el Fénix volverá a renacer en sus escritos. VALE.

El Licenciado Josef Ortiz de Villena

1636

FAMA | POSTHVMA | A | LA VIDA Y MVERTE | DEL Doctor Frey Lope Felix | de Vega Carpio. | Y ELOGIOS PANEGIRICOS A LA | INMORTALIDAD DE SV NOMBRE. | ESCRITOS | POR LOS MAS ESCLARECIDOS INGENIOS. | SOLICITADOS | POR EL DOCTOR IVAN PEREZ de Montalvan | QVE | AL EXCELENTISSIMO SEÑOR | Duque de Sessa, Heroyco, Magnifico, y Soberano | Mecenas del que Yaze. | OFRECE, PRESENTA, SACRIFICA, Y CONSAGRA. | 56 | En Madrid, en la Imprenta del Reyno. Año 1636. | [Filete.] | A costa de Alonso Perez de Montaluan, Librero de su Magestad.

26. En el texto —creo que por mero lapsus mentis—, «a todos los reyes sus predecesores».

27. En el texto «se hallarà». Quizá la tilde grave se haya cruzado con la de nasalización «se hallarã», que indicaría que el verbo está en plural, como pide la coherencia sintáctica. 
[ff. $155 \mathrm{v}-157 \mathrm{r}]$

A LA MUERTE DEL PRODIGIO DE ELOCUENCIA

y Fénix de España, frey Lope Félix de Vega Carpio, DEL HÁBITO DE SAN JUAN, PROCURADOR FISCAL DE LA CÁMARA APOSTÓLICA

Y FAMILIAR DEL SANTO OFICIO DE LA INQUISICIÓN.

Por el licenciado Josef Ortiz de Villena, su amigo

EleGía FunERAL

Riberas que en el claro Manzanares

os envidian los ríos y los mares,

ya de tantos ingenios celebradas,

frondosas y esmaltadas

de fértiles verbenas y amarantos;

aves que en dulces cantos

con sonora armonía

a las primeras márgenes del día

vuestros celos y amores

contastes a las flores,

vestid eterno luto:

ni lleve el prado flor ni el árbol fruto.

Erato lastimosa,

haz mi contemplación más estudiosa,

para que pueda lúgubre mi pluma

escribir de su muerte breve suma,

bañándola en cristal de llanto mío.

Óyeme, Manzanares, claro río;

los ojos vuelve a tu soberbia puente,

que a las humildes sienes de tu frente,

verde guirnalda rica

el alto cielo aplica

en los reyes de España,

cuyas carrozas tu corriente baña;

si alguna vez ${ }^{28}$ lloraste

28. En la edición de 1636: «voz». Parece errata. 
$\mathrm{y}$ tus ojos cegaste

con turbulenta arena,

llora agora mi pena,

de negras ondas oprimido y preso,

efecto de este trágico suceso.

Aquella Parca, cuyo reino impío

de su caduco estío

tiene a los pies coronas y laureles,

rayo de los soberbios capiteles

como de las cabañas pastoriles,

que iguala cetros y azadones viles,

su guadaña sangrienta esgrimió fiera

contra el fénix que tuvo nuestra esfera,

contra el cisne de Apolo, a quien coronan

las Musas, que su ingenio galardonan

de laureles divinos este día,

a pesar de la invidia, fiera harpía.

Mas ¿por qué callo el nombre en mal tan fuerte?

A Lope hirió la vengativa muerte.

Lope de Vega, que con labios de oro,

fue de estos siglos el mayor tesoro.

Fuiste, sin duda, del Parnaso el ave,

venciendo al cisne que volar más sabe.

No llamo tus conceptos peregrinos,

que atrás dejaron griegos y latinos.

Con tu elegancia dejas siempre absortas

(y en la justa venganza te reportas)

de los zoílos las censuras vanas,

que la prudencia de tus nobles canas

tapó a la invidia loca

la venenosa boca.

¿Quién, sino tú, fertilizó la vega, por el rico tesoro que le entrega, al claro Manzanares,

aunque son sus ingenios singulares,

que ya en mansa corriente ha confesado, siendo de tu elocuencia celebrado, que solo fue tu pluma 
de las deidades suyas fénix Numa.

Tus diversas comedias son sirenas

que obligan a olvidar las graves penas, y a los oyentes adormecen tanto que parece verdad y es dulce encanto.

Los libros que escribiste celebrados serán siempre en los siglos, y estimados.

Que, en oyendo tu nombre, es evidente que aplaudidos serán eternamente.

¡Oh prodigio de ciencia!, ¿quién hay que pueda hacerte competencia?

¡Oh famoso español!, joh varón fuerte!, que hallaste nueva vida por la muerte, callo las alabanzas de tu gloria, que faltan muchas hojas a tu historia, que cantarán las Musas

en acciones difusas,

con pluma altiva, heroica y arrogante, en láminas de bronce o de diamante; mas tu virtud, que es la mayor hazaña, llore en el triunfo de tu muerte España, pues por que Fama su arrogancia tope, también la muerte quiso ser de Lope.

$\mathrm{Al}$ fin murió el ingenio, la agudeza, la lengua castellana, la pureza con que la habló con elegancia tanta que su elocuencia a todo el mundo espanta; mas sus versos tendrán dichosos fines, que en diciendo «Es de Lope», en los confines del contrapuesto sur resuenen tanto sonoros ecos de su dulce canto por la firme opinión de sus escritos, pródigos, inexhaustos, infinitos; que es lauro que los méritos corona la humildad que las obras galardona. 


\section{7}

LA VEGA DEL PARNASO | POR EL FENIX DE ESPAÑA | Frey Lope Felix de Vega Carpio, del Abito de | San Iuan, Procurador Fiscal de la | Camara Apostolica. | DIRIGIDA | AL EXCELENTISSIMO SEÑOR DON LVIS | Fernandez de Cordoua, Cardona, y Aragon, Duque de Sessa, \&c. | 74 | [Escudo del mecenas.] | En Madrid, En la Imprenta del Reyno, Año 1637.

[Preliminares, f. 3r-v, s. n.]

El Licenciado Josef Ortiz de Villena

\section{A los aficionados de frey Lope FéLIX DE VeGA CARPIO}

Pedían tantas personas estos versos de Lope que andaban en fragmentos por haberse impreso pocos en diversos tiempos, como escritos a diversos propósitos, y siendo lo que con más estudio se conoce entre sus líricos, que me pareció - cuando era vivo- pedirle que los juntase, copiándole muchos de los que no estaban impresos y dándole los que no tenía, por cumplir con los deseos de los aficionados a sus obras. Y por que le viniese mejor el nombre a La vega del Parnaso, se añadieron las mejores comedias que ha compuesto, por que, como en las vegas hay tanta variedad de plantas, árboles y flores, así pudiesen entretenerse los que la leyeren en tan diversos géneros de poesías, y no siendo menos conforme a su nombre el título del libro. Y por que no se cansen en subir al monte, hallando más cerca las fuentes de Hipocrene y Helicona, aunque ya su dificultad, merced de la fertilidad de los tiempos, se ve tan trillada y fácil que en este no hubiera dicho Garcilaso:

A la cumbre difícil de Helicona...

Ni Ovidio, en el primero de su Metamorfosis:

mons ubi verticibus petit arduus astra duobus, nomine Parnasus... 
Y Mantuano:

Quae fugit ardue in alti Parnasi iuga...

De suerte que la subida al monte es difícil si se considera en el fin, que es el laurel de la eternidad, y fácil al juicio de los que en esta edad, engañados de términos escuros y inauditos, en vez de aumentarla y ennoblecerla, infaman y destruyen nuestra lengua. Así, dijo Fernando de Herrera, en el Comento a Garcilaso,

que nuestra lengua arribaría a la cumbre que la griega y latina si nosotros, con impiedad, no la desamparásemos.

Y más adelante, alabando sus versos de Garcilaso, que son todos ilustrados de claridad, y en esta razón, prosigue:

que las Musas escogiesen esta lengua de Garcilaso siempre que hablaren castellano.

Bien sé que es dar voces al viento, y que me dirán:

Abluis Aetiopem, quid frustra?

Porque, con cuatro voces peregrinas y algunos desaforados hipérboles - gran fiesta del ignorante vulgo-, se sueñan muchos haber llegado a la infinita majestad del arte.

Estos versos de Lope salen a luz de su misma claridad cuando estaban tan cerca de perderse por la poca estimación en que él, viviendo, tuvo cuanto escribía, humildad que, a no haber sido en su naturaleza virtud, hubiera sido en su desconfianza digna de reprehensión. Y si de esto se disgustare la calumnia o la multitud, no importa; que los mismos versos del libro —que el ilustrísimo señor don Rodrigo de Acuña, meritísimo arzobispo de Lisboa, en una carta llama «claridad concetuosa»— responderán por sí. 
[f. $1 \mathrm{r}]$

$$
\text { EL SIGLO DE ORO }
$$

\title{
AdVERTENCIA A LOS LECTORES ${ }^{29}$
}

Parece que, cuando este cisne divino espiraba, con más melodía y sonora voz cantaba para suspender a todos con la dulce armonía de sus versos, pues el día antes que le diese la enfermedad, hizo con tanta elegancia y elocuencia esta silva moral $\mathrm{Al}$ siglo de oro y el soneto que va impreso tras ella a la muerte de un caballero portugués, en que parece que pronosticó después de su muerte en lo que había de estimarse hombre tan eminente e insigne como fue. Advierta el lector que fueron los últimos versos que compuso este soneto.

\section{9}

LAGRIMAS | PANEGIRICAS | A | LA TENPRANA MVERTE | DEL GRAN POETA, I TEOLOGO | Insigne Doctor Iuan Perez de Montalban, Cle- | rigo Presbitero, i Notario de la Santa In- | quisicion, Natural de la Inperial | Villa de Madrid. | LLORADAS I VERTIDAS POR LOS | mas Ilustres Ingenios de España. | RECOGIDAS I PVBLICADAS | por la estudiosa diligencia del Licenciado | don Pedro Grande de Tena, su mas | aficionado Amigo. | DEDICADAS I OFRECIDAS A ALONSO | Perez de Montalban, Padre del Difunto, i Librero | del Rei nuestro Señor. | [Florón.] | En Madrid. En la Inprenta del Reino. Año M.DC. XXXIX.

[ff. $37 \mathrm{r}-38 \mathrm{r}$ ]

\author{
Elegía Funeral a la MUERTE \\ DEL doctor Juan PÉrez de Montalbán. \\ Por el licenciado Josef Ortiz de Villena, \\ SU GRANDE AMIGO Y AFICIONADO
}

Campos de la segunda primavera que apenas en la yerba persevera, seco despojo, cuyo humor interno

29. Aunque este texto carece de firma, parece verosímil atribuirlo a Ortiz de Villena, como han hecho sus modernos editores (Conde y Gutiérrez Valencia 2015:87). 
a quien el sol el breve curso eterno deja en los brazos de la noche fría, si en vuestra soledad hallar solía lugar contemplación más estudiosa, hállela en vos mi Erato lastimosa para que pueda, lúgubre, mi pluma atreverse a escribir en breve suma con tan grande dolor una epigrama de aquel que, desatado en pura llama, pasó de esta mortal a eterna vida, en brazos de su fama merecida.

Lágrimas salgan de mis tristes ojos, publiquen la ocasión de mis enojos, y con la fuerza del dolor violento mi voz se esparza por el vago viento, repitiendo el dolor mayor grandeza en el áspero ardor de la tristeza.

Cubra de luto, pues, el sol la frente y haga que en Manzanares su corriente produzga abrojos y sepulte flores.

Canten endechas ninfas y pastores, pues ya la Parca, con grosero estilo, cortando sin piedad el vital hilo, su furia apresuró con furia tanta ${ }^{30}$ que le añudó la voz a la garganta a aquella filomena, cuyo acento escuchó el orbe atento,

si bien el eco recogió el sonido que dura en nuestro oído, de MONTALBÁN el nombre, cuyo ingenio ave de Apolo fue su dulce genio, pues muriendo renace su memoria, por coronar con su laurel su gloria.

Llorad, ¡oh Musas!; enseñadme a honrarle; prestadme vuestra voz para llorarle;

30. Así en la edición de 1639. La repetición poco feliz de furia puede deberse a una mera errata. Quizá el ocasional poeta de este homenaje fúnebre quiso escribir algo así como su suerte apresuró o su sino apresuró o su muerte apresuró, o bien su furia apresuró con fuerza tanta. 
al túmulo asistid enternecidas,

en vuestra misma luz siempre encendidas.

Desaliñada, pues, vuestra belleza

manifieste su trágica tristeza.

Dilátese, mortal, el desconsuelo.

Brame el mar, gima el aire y clame el suelo

hoy que a su vida se atrevió la muerte,

pues en lo muerto lo inmortal advierte

quien en su muerte el desengaño mira

mortal, cuando a inmortal su ingenio aspira;

que su divino ser hizo más cierto

el quedar inmortal después de muerto.

¡OH MONTALBÁN!, oh ingenio peregrino, que el ser humano te hace más divino, prodigio en estos siglos milagroso, que ilustras por insigne y por famoso nuestra edad con tu ciencia y tus escritos, pródigos, ineshaustos, infinitos.

Cisne fuiste y lisonja de los vientos; cisne, reparte, pues, dulces acentos. Águila regia, al sol rayos bebiste; águila, ofrece plumas, que vestiste, a la lengua, a la voz, al verso, al canto, pues hoy te soleniza primor tanto. El Parnaso enturbió su cristal puro y el sol anocheció en eclipse escuro; las Musas sin tu voz enmudecieron; desgreñadas las ninfas te plañeron; los ingenios de España superiores te tributaron públicos honores.

¡Qué mucho llore el mundo la falta de tu ingenio tan profundo!

¿Quién habrá que presuma

ser feliz heredero de tu pluma?

Todos te canten, y te lloren todos, su amor mostrando por diversos modos, pues ya vives en paz, pisando flores,

bañado de inmortales resplandores 
en los campos bellísimos del cielo, y en perpetuo descanso, sin recelo de volver a esta patria mal segura desde su esfera reluciente y pura.

\title{
1644
}

FIESTAS | DEL SANTISSIMO | SACRAMENTO, | REPARTIDAS EN DOZE AVTOS | Sacramentales, con sus Loas, y Entremeses. | Compuestas por el Phenix de España Frey Lope Felix | de Vega Carpio, del Abito de San Iuan. | RECOGIDAS POR EL LICENCIADO IOSEPH ORTIZ DE | Villena, y dedicadas al Tumulo, y Fama inmortal suyo. | [Viñeta con un cáliz y dos ángeles adorándolo.] | Loado sea el Santissimo Sacramento, y la limpia Concepcion de la Virgen | Santissima, Concebida sin mancha de pecado original, y el paso | doloroso de su Martirio, y Soledad. | [Filete.] | Con licencia : En Çaragoça, por Pedro Verges, Año M.DC.XXXXIIII. | A costa de Pedro Verges Mercader de libros, En la Calle de Toledo.

[Preliminares, ff. 2r-3r, s.n.]

\author{
Al tÚMULO Y FAMA INMORTAL \\ de frey Lope Félix de Vega Carpio, \\ DEL hábito de SAN JuAN, \\ el licenciado Josef ORtiz de Villena, \\ SU VERDADERO AMIGO, \\ DEDICA ESTOS AUTOS SACRAMENTALES
}

Muere Lope, y su patria compasiva recuerdos justos a su muerte ofrece por que inmortal en su memoria viva.

Y este dolor, que en todo el orbe crece, es en mi rudo ingenio atrevimiento, si bien de sentimiento no carece.

Solo sacar pretendo del intento dar a entender que fui su fiel amigo y que estimé su gran merecimiento.

Y no atendiendo aquesto, es Dios testigo 10 
que de su fértil genio aficionado, la opinión verdadera siempre sigo.

Tú fuiste aquel varón más señalado que ha producido nuestra madre España, a quien con tus escritos has honrado.

En ti mostró naturaleza, estraña cuanto increíble, gran sabiduría, siendo de su poder notable hazaña.

El competir contigo es tiranía, sujeta a la sentencia de discretos, que descubre ignorante fantasía.

Tus versos, conocidos por perfetos en lo lírico, heroico y metro grave, a ninguna objeción están sujeros.

Eres, sin duda, del Parnaso el ave que con veloz y levantado vuelo venciste al cisne que volar más sabe.

Mas ya faltaste del hispano suelo, atrás dejando griegos y latinos, sin descansar hasta llegar al cielo.

No llamo tus conceptos peregrinos, porque les toca de derecho el nombre de castos, agradables y divinos.

$\mathrm{Y}$ quien te conoció, que no se asombre que haya escrito, con caudalosas venas, ${ }^{31}$

más que docientos, solamente un hombre.

Tus diversas comedias son sirenas que a los oyentes adormecen tanto que obligan a olvidar las graves penas.

Allí se ve tan eficaz el llanto,

las fábulas y historias retratadas, que parece verdad, y es dulce encanto,

En el orbe se logran estimadas, dando gusto y dotrina al relevante

31. El endecasílabo, tal y como se nos ha trasmitido, con acentos en las sílabas $1^{\mathrm{a}}, 3^{\mathrm{a}}, 7^{\mathrm{a}}$ y $10^{\mathrm{a}}$, es muy incorrecto. Es probable que Ortiz de Villena pretendiera seguir hablando en segunda persona al difunto (que hayas escrito en caudalosas venas); pero al componer el verso siguiente, con un sujeto en tercera persona (un hombre), corrigió la sintaxis sin percatarse de que rompía el preceptivo ritmo del verso. 
ingenio, por que siga sus pisadas.

Y para el vulgo rudo, que ignorante aborrece el manjar costoso, guisa el plato del gracioso estravagante, con que les hartas de contento y risa, gustando de mirar sayal grosero más que sutil y cándida camisa.

Aquí dejar tus alabanzas quiero por no agraviarlas más, que me he engolfado ignorante, mas no cual lisonjero.

Tratar de hallarlas fondo es escusado, porque en tu mar profundo los pilotos de mayor opinión se han anegado.

Mas no por esto mis desinios rotos han de quedar, pues has de ser amparo de estos autos que hiciste, tan devotos;

porque a la sombra de tu genio claro nadie osará ofendellos, que mi vena, temiéndose la herida, fue al reparo. AMIGO Y CAPELLÁN TUYO, VILLENA.

[Preliminares, f. 3v, s.n.]

\section{El licenciado Josef Ortiz de Villena}

\section{A LOS AFICIONADOS DE FREY LOPE FÉLIX DE VEGA CARPIO}

Letor amigo, muchos días ha que he deseado sacar a luz algunos autos sacramentales que aquel Fénix de España con tanta erudición escribió, y importunado de amigos, he dado a la estampa este libro, a quien intitulo Fiestas del Santísimo Sacramento repartidas en doce autos sacramentales, cada uno con su loa y su entremés, para que se hallen hechas las fiestas en los lugares como se representaron en esta corte. Recíbelos con el gusto que has recebido los demás libros suyos. Vale.

El licenciado Josef ORtiz de Villena 
[Preliminares, f. 4r-v, s.n.]

\author{
Al Santísimo Sacramento del altar \\ OFRECE ESTAS ESTANCIAS \\ EL LICENCIAdo Josef ORTIZ DE VILLENA
}

Divino pan por quien es cielo el suelo, donde está el cuerpo del amante Cristo en tanta cantidad como en el cielo asiste agora, y en la cruz fue visto, sin exceder los términos del velo

en que al gustar, tocar y ver resisto, porque en tus maravillas excelentes sin el sujeto están los acidentes.

De tal manera quedas, pan sagrado, en su cuerpo divino convertido,

ni por las muchas formas aumentado, ni por mucho comer disminuido; que no eres su materia, ni has quitado un átomo a su cuerpo, y dividido eres el mismo todo en toda parte, sin que de Dios un átomo se aparte.

Cuando te tengo yo en la indigna mano y te miran devotos nuestros ojos, ni se toca tu cuerpo soberano, ni vemos más que cándidos despojos.

Esto por sí, como es a la fe llano, aunque el lince mortal se ponga antojos; que estas cifras de amor que el alma abrasan cerca no más de las especies pasan.

Los que te comen y desprecian tanto que vuelven, pan divino, a su error ciego, son Absalones de ese cuerpo santo, que le convidan y le matan luego. A ti la voz, el coro, el plectro, el canto; a ti, abrasados de divino fuego, los amores, las fiestas y las glorias celebren triunfos, de tu cruz vitorias. 